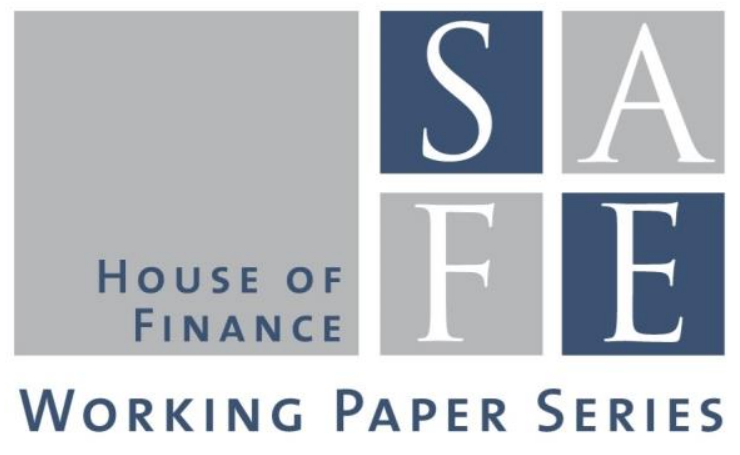

Mario Bellia - Roberto Panzica - Loriana Pelizzon - Tuomas Peltonen

\title{
The Demand for Central Clearing: To Clear or Not to Clear, That is the Question
}

SAFE Working Paper No. 193 


\section{Non-Technical Summary}

The Global Financial Crisis exposed a number of systemic weaknesses in the market for over-thecounter (OTC) derivative securities. In response, the G20 Leaders in 2009 initiated a fundamental overhaul of OTC derivatives markets with the objectives to mitigate systemic risk, improve transparency, and protection against market abuse. As a regulatory response, the U.S. Congress signed the Dodd-Frank Wall Street Reform and Consumer Protection Act (DFA) into law in July 2010, and the European Parliament and the Council of Ministers agreed on the European Market Infrastructure Regulation (EMIR) in August 2012.

While in Europe the credit default swap (CDS) indices must be cleared under the MiFID regulation, a rule for single name CDS reference entities has not yet been finalized, therefore the decision to clear single name CDS is still voluntary to date.

The research question of this paper is why only some sovereign CDS transactions currently eligible for central clearing are cleared while others are not. We investigate this from a clearing member perspective, and focus on what are the drivers of this decision.

In particular, we analyze three main drivers for the decision to clear: 1) the liquidity and riskiness of the reference entity; 2) the credit risk of the counterparty; and 3) the clearing member's portfolio net exposure with the CCP.

We investigate empirically the relevance of these different drivers in the decision to clear by using a unique regulatory dataset: the confidential European trade repository data on single-name sovereign CDS transactions ruled by the EMIR. The database used for our analysis includes all derivatives transactions by EU financial institutions in 2016. However, our analysis focuses on the most traded European sovereign CDS contracts: Italy (IT), France (FR) and Germany (GE).

Our results demonstrate that the large majority of the transaction cleared are between CCP clearing members, while in our dataset there is almost no evidence of clearance of transactions by nonclearing members, independently whether they are subject to capital requirements or not.

Focusing on contracts that are eligible for clearing, we investigate the factors that drive clearing members' decision to clear. First, we find that both capital costs and margin costs are relevant for the decision to clear, with some differences among the three sovereign CDS contracts. For the Italian sovereign CDS, the counterparty credit risk exposure is more relevant than the margin costs in the decision to clear, while for the German sovereign CDS contracts margin costs are the most important. Instead, for the French sovereign CDS contract it is difficult to disentangle which of the two main drivers prevails. Second, we find that when a net seller of a specific sovereign CDS buys an additional contract, its propensity to clear increases. This finding is robust across reference entities, indicating that portfolio positions with the CCP also matter on the decision to clear the single contracts. Finally, we find that the counterparty credit risk alone is an important incentive to clear a contract, as this factor is significant for all analyzed reference entities.

Our study has several potential policy implications. First, it shows that the indirect clearing of nonclearing members, independently whether they are subject to capital requirements, is very low. Thus, regulators should further investigate reasons for this, and better understand the cost factors and other potential obstacles for client clearing. Second, our results show that factors impacting the incentives for central clearing are not the same for all analyzed CDS reference entities. Finally, our analysis shows that the decision to clear is also related to net exposure with the CCP, in addition to the characteristics of the contract and the counterparty credit risk. 


\title{
The Demand for Central Clearing: To Clear or Not to Clear, That is the Question Mario Bellia* Roberto Panzica* Loriana Pelizzon* Tuomas Peltonen ${ }^{\dagger \dagger}$
}

First Version: June 1, 2017

This version: January 19, 2018

\begin{abstract}
This paper analyses whether the post-crisis regulatory reforms developed by globalstandard-setting bodies have created appropriate incentives for different types of market participants to centrally clear Over-The-Counter (OTC) derivative contracts. Beyond documenting the observed facts, we analyze four main drivers for the decision to clear: 1) the liquidity and riskiness of the reference entity; 2) the credit risk of the counterparty; 3) the clearing member's portfolio net exposure with the Central Counterparty Clearing House (CCP) and 4) post trade transparency. We use confidential European trade repository data on single-name Sovereign Credit Derivative Swap (CDS) transactions, and show that for all the transactions reported in 2016 on Italian, German and French Sovereign CDS 48\% were centrally cleared, $42 \%$ were not cleared despite being eligible for central clearing, while $9 \%$ of the contracts were not clearable because they did not satisfy certain CCP clearing criteria. However, there is a large difference between CCP clearing members that clear about 53\% of their transactions and non-clearing members, even those that are subject to counterparty risk capital requirements, that almost never clear their trades. Moreover, we find that diverse factors explain clearing members' decision to clear different CDS contracts: for Italian CDS, counterparty credit risk exposures matter most for the decision to clear, while for French and German CDS, margin costs are the most important factor for the decision. Clearing members use clearing to reduce their exposures to the CCP and largely clear contracts when at least one of the traders has a high counterparty credit risk.
\end{abstract}

Keywords: Credit Default Swap (CDS), Central Counterparty Clearing House (CCP), European Market Infrastructure Regulation (EMIR), Sovereign.

JEL Classification: G18, G28, G32.

${ }^{*}$ LOEWE Center SAFE, Goethe University Frankfurt, Theodor-W.-Adorno-Platz 3, 60323 Frankfurt am Main, Germany.

${ }^{\dagger}$ European Systemic Risk Board, Secretariat, Sonnemannstrasse 22, 60314 Frankfurt am Main, Germany.

†Disclaimer: The views expressed in the paper are those of the authors and do not necessarily reflect the views of the ESRB or its member institutions. We are grateful to Roberto Stok for his very helpful comments as well as IT and data support. We thank the ESRB CCP Task Force for their useful comments, particularly Pietro Stecconi and Daniela Russo. We also thank Giulio Girardi for the fruitfull discussion about the main drivers for the decision to clear. Mario Bellia, Roberto Panzica and Loriana Pelizzon thank the Research Center SAFE, funded by the State of Hessen Initiative for Research (LOEWE), for financial support. 


\section{Introduction}

The Global Financial Crisis exposed a number of systemic weaknesses in the market for over-the-counter (OTC) derivative securities. In response, the G20 Leaders in 2009 initiated a fundamental overhaul of OTC derivatives markets with the objectives to mitigate systemic risk, improve transparency, and protect against market abuse. The G20 Leaders made five commitments to reform OTC derivatives markets: 1) standardized OTC derivatives should be centrally cleared; 2) non-centrally cleared derivatives should be subject to higher capital requirements; 3) non-centrally cleared derivatives should be subject to minimum standards for margin requirements; 4) OTC derivatives should be reported to trade repositories; and 5) standardized OTC derivatives should be traded on exchanges or electronic trading platforms, where appropriate. ${ }^{1}$

As a regulatory response, the U.S. Congress signed the Dodd-Frank Wall Street Reform and Consumer Protection Act (DFA) into law in July 2010, and the European Parliament and the Council of Ministers agreed on the European Market Infrastructure Regulation (EMIR) in August 2012.

While in Europe and in the US credit default swap (CDS) indices must be cleared under the MiFID regulation, ${ }^{2}$ a rule for single name CDS reference entities has not yet been finalized, therefore the decision to clear single name CDS is still voluntary to date. From the BIS reports ${ }^{3}$ one can deduce that the share of cleared derivatives contracts continues to be a relatively small fraction of the total notional amount outstanding (around $37 \%$ as reported by Financial Stability Board, 2017), though this fraction is increasing over time. While there is not yet a regulatory obligation to clear single-name contracts in the EU and in the US, there may be relevant economic incentives to do so. The research question of this paper is why only some sovereign CDS transactions currently eligible for central clearing are

\footnotetext{
${ }^{1}$ See the FSB report to G20 Leaders on progress in financial regulatory reforms, available at http: //www . fsb.org/2017/07/fsb-reports-to-g20-leaders-on-progress-in-financial-regulatory-reforms/.

${ }^{2}$ The Markets in Financial Instruments Directive 2004/39/EC and Exchange Act Section 3C(b)(4)(B).

${ }^{3}$ See the BIS over-the-counter (OTC) derivatives statistics database, available at http://stats.bis . org/statx/srs/table/d10.4?p=20162\&c=.
} 
cleared while others are not. We investigate this from a clearing member perspective, and focus on what are the drivers of this decision by considering factors impacting (i) collateral cost, (ii) capital cost and (iii) transparency.

We investigate empirically the relevance of these different drivers in the decision to clear by using a unique regulatory dataset: the confidential European trade repository data on single-name sovereign CDS transactions ruled by the EMIR. The database used for our analysis includes all derivatives transactions by EU financial institutions in 2016. However, our analysis focuses on the most traded European sovereign CDS contracts: Italy (IT), France (FR) and Germany (GE). The choice of the CDS contracts is not done only due to the trading activity but also to reflect differences in risk characteristics of the underlying reference entities. Finally, we concentrate on sovereign CDS contracts, because they are the contracts mostly traded by European institutions, and therefore well represented in our database (see Abad et al. (2016)).

To our knowledge, our paper is the first that investigates empirically the fraction of eligible contracts for clearing and the drivers of the decision to clear a contract. We find that in our sample about $48 \%$ of the notional amount traded in 2016 has been cleared, $42 \%$ were not cleared despite being eligible for central clearing, while $9 \%$ of the contracts were not clearable because they did not satisfy certain Central Counterparty Clearing house (CCP) clearing criteria.

However, we notice a strong differentiation in the decision to clear between clearing members and non-clearing members. Clearing members account for $96.5 \%$ for the gross notional amount traded in our sample, and they are net buyers for an aggregate 9.7 billion US dollars, a size comparable to net selling position of non-clearing members that are not subject to capital requirements $(-8.1 \mathrm{~B} \$)$. For clearing members, we find that the fraction of cleared contracts is larger, $53 \%$, while the fraction of non-eligible contracts is $8 \%$. All clearing members are subject to capital requirements, and have capital charge benefit if they clear the contracts. Nevertheless, among non-clearing members, both those subject to capital 
requirements (banks and insurances) and the others not subject to capital requirements, do not clear their CDS contracts to a large extent. This might be due to two main reasons. First, capital requirements charged for the default funds for central clearing as well as the costs for becoming a clearing member are too high for them. Second, the indirect clearance is also more costly for them than the benefit they get from the reduction of the capital requirement charge.

Regarding the drivers of the decision to clear for clearing members, we look at different characteristics of the contracts that could capture the differences in terms of margin and capital costs between cleared and not cleared contracts. Concerning collateral requirements, one key aspect is the existing disparity between initial and variation margins between cleared and non cleared contracts. In fact, for the most part, margins are not exchanged or are lower in the OTC transactions, while they are always required for cleared trades (at least until the new regulation on OTC derivatives is in place). On the other side, Counterparty Credit Risk (CCR) capital charge introduced by the Basel III for bilateral trades is larger for non cleared transactions than for centrally cleared trades. This should provide a relevant incentive to clear, at least for institutions subject to capital requirements. ${ }^{4}$

We model the incentives to clear (or not) a contract based on the characteristics of the contract that affect both the margin setting by CCPs and CCR capital requirements such as (i) price; (ii) change in the price; (iii) volatility of the price; (iv) liquidity of the contract; and (v) size of the transaction. In principle, more risk could encourage clearing in order to reduce $\mathrm{CCR}$ capital requirements, but on the other side, more risk means larger margins and therefore costs. Only by investigating this issue empirically we can disentangle which element prevails.

Moreover, one key aspect that should be considered is that the counterparties must

\footnotetext{
${ }^{4}$ In the paper we refer to the difference in terms of CCR capital requirements between cleared and not cleared transactions, but in general, a large counterparty credit risk exposure should already be an incentive to clear the contract, independently from the different treatment in terms of capital requirements. However, since this was not a sufficient incentive in the past to clear contracts, we prefer to refer to capital cost reduction of cleared contracts as one of the drivers to clear the contract and not just the CCR exposure.
} 
agree on the decision to clear, therefore not only the characteristics of the contract are relevant for the decision to clear in terms of margin costs but the individual incentives of each trader related to their portfolio exposures with the CCP also matters. For this reason, we look at the net position at CCP because it might be a relevant variable for the decision to clear. If a transaction reduces the counterparty's outstanding exposures against the CCP, the willingness to clear is expected to be larger since it will reduce margin requirements. Another main incentive to clear refers to CCR itself, independently on the size of the exposure or the riskiness of the reference entity. The CCR plays an important role since the "safer" counterparty should prefer to clear, at least above a certain level of CCR, other things the same. We capture the CCR itself by looking at the CDS spread of the traders.

The last main driver that we consider for the decision to clear is the difference in posttrade transparency between cleared and non cleared contracts. Cleared contracts are subject to post-trade transparency through the CCP. Non cleared contracts are not subject to posttrade transparency at least till the beginning of 2018 when MiFID II would be effective and the post-trade reporting requirements also for OTC derivatives are in place. Transparency might offer speculation opportunities to other traders, in particular if the size of the transaction is large. Therefore, if this is an important driver in the decision to not clear the contract, we should find that the larger contract size lowers the incentive to clear the contract.

Focusing on clearing members, our analysis reveals that there are significant differences in the main drivers of the decision to clear among the three sovereign CDS contracts we considered. The riskiness of the reference entity, measured by the level of the CDS spread, increases the probability to go through central clearing. However, daily increases in the CDS spread or CDS spread volatility reduce the probability of clearing for German and French sovereign CDS but increase it for the Italian sovereign CDS. It seems therefore that the main drivers of the decision to clear for the Italian CDS are margin costs instead for France and Germany CCR capital requirements. Furthermore, higher notional amounts are more likely to be cleared across all three sovereign CDS contracts, indicating that CCR capital 
requirement benefits prevail with respect to transparency issues.

We investigate how counterparty credit risk stand-alone effects the decision to clear by examining the riskiness of the two counterparties that agree to trade. We find that both the seller and the buyer manage counterparty exposures strategically choosing to clear when the counterparty is riskier. This means that the benefit in the reduction of CCR capital requirements provide strong incentives for clearance to clearing members.

Consistent with the notion that clearing members need to post greater initial and maintenance margins with the CCP when their net exposure with the CCP is larger, we find evidence that when the trade reduces the counterparty's outstanding net positions with CCP, the probability to clear the trade is higher. Thus, overall we find that the decision to clear is a complex decision not just related to a single contract but to the portfolio holdings and total exposures with the CCPs, as well as to the ability of CCP to post rules for automate netting/cancellation of offsetting contracts.

The paper is organized as follows. In Section 2 we describe the regulatory framework and review related literature. In Section 3 we formulate the hypotheses tested in the paper. In Section 4 we briefly describe the dataset. In Section 5 we provide an overview of trading and clearing in sovereign CDS. In Section 6 we report the empirical evidence regarding the decision to clear or not an eligible contract and finally Section 7 concludes.

\section{Regulatory framework and related literature}

The regulatory framework underlying the paper follows the agreement the G20 Leaders reached in 2009, which requested that OTC derivatives contracts should be cleared through CCP. This decision came after the Global Financial Crisis of 2007-2009, which highlighted the systemic weaknesses in the financial market infrastructure, especially for the OTC derivative securities. In particular, the market for CDS was characterized by highly concentrated and interconnected positions that serve as a conduit for the transmission of systemic risk in 
the event of a counterparty failure. Since that, the regulators have advanced a number of reforms that are likely to affect the incentives for central clearing of these contracts. To improve coordination, the OTC Derivatives Coordination Group was formed. ${ }^{5}$

The primary regulatory response has been in the US in 2010, where the U.S. Congress signed the Dodd-Frank Wall Street Reform and Consumer Protection Act (DFA), and in Europe, where the European Parliament as well as the Council of Ministers agreed on the European Market Infrastructure Regulation (EMIR) in August 2012. Both of these reforms are designed to promote financial stability by improving accountability and transparency in the financial system. In the US, the Securities and Exchange Commission (SEC) and the Commodity Futures Trading Commission (CFTC) have been delegated to implement the DFA, while in Europe, the European Securities and Markets Authority (ESMA), has been delegated for the implementation of the EMIR.

In the Basel III framework (Bank for International Settlements, 2012), banks' collateral and mark-to-market exposures to the central counterparties are subject to a lower risk weight, while the default fund exposure to the $\mathrm{CCP}$ is subject to capital requirements. On the contrary, the regulatory reforms of the derivatives markets include requirements to exchange initial and variation margins for non-centrally cleared derivatives exposures. The two main regulatory acts are the "Margin requirements for non-centrally cleared derivatives" (BCBSIOSCO) and the "Principles for Financial Market Infrastructures" (CPMI-IOSCO). In view of these regulatory changes, the OTC Derivatives Assessment Team at BIS performed a study in 2014 to assess incentives to centrally clear OTC derivatives (Bank for International Settlements, 2014). This survey identified that the main drivers for the decision to clear are margin costs and capital costs. Moreover, it performed a quantitative analysis and found that CCP's clearing member banks have incentives to clear centrally, while incentives for

\footnotetext{
${ }^{5}$ The institutions belonging to the OTC Derivatives Coordination Group are: the Financial Stability Board (FSB), the Basel Committee on Banking Supervision (BCBS), the Committee on the Global Financial System (CGFS), the International Organization of Securities Commissions (IOSCO) and the Committee on Payments and Market Infrastructures (CPMI), previously known as the Committee on Payment and Settlement Systems (CPSS).
} 
market participants that clear indirectly are less obvious. Our paper aims to shed some light on these issues.

In 2017, the OTC Derivatives Coordination Group agreed to make an evaluation of the impact of G20 reforms on incentives to centrally clear the OTC derivatives. The Derivative Assessment Trades (DAT) at FSB conducted a study in order to understand whether the G20 financial regulatory reforms have achieved their intended outcomes. The report stressed the difficulties in identifying the fraction of standardized OTC contracts eligible to clear, and therefore to measure the total proportion of standardized OTC derivatives that are centrally cleared. The report also indicates that more favorable regulation for cleared transactions combined with higher OTC transactions capital requirement would incentivize banks to clear new transactions. The DAT report provides evidence that the number of contracts cleared related to interest rate derivatives and credit derivatives has increased markedly after 2009. The report shows that, at the end of 2016, the central clearing rate of the stock of outstanding CDS is estimated to have reached $28 \%$ globally, and $37 \%$ in EU (Financial Stability Board $(2017)) .^{6}$

Both the theoretical and empirical literature on central clearing is growing, in particular on the CDS market, especially after ICE launched the first dedicated clearing house in March 2009. However, already before the Global Financial Crisis, there were authors suggesting that an important public policy issue is whether and how to (i) encourage the use of the CCPs; and (ii) standardize part of the OTC derivative market. Bliss and Steigerwald (2006) recognize that CCPs bring a bundle of interrelated services to the market, including credit risk management, delegated monitoring, and liquidity enhancement. In particular, they stressed that one of the key advantages of CCP is that credit risk becomes homogenized, at least as far as clearing members are affected. Moreover, in a centrally cleared derivatives

\footnotetext{
${ }^{6}$ Our paper complements the FSB work and extends it along the following dimensions. First, our study is able to distinguish whether the OTC derivatives contracts are eligible for clearing or not, therefore increasing the accuracy of the evidence on the extent of central clearing occurring. Second, by focusing on certain asset derivative class, sovereign CDS in our case, we are able to dig deeper into the main drivers of the decision to clear the derivatives contract.
} 
market, the clearing house typically sets the rules for the automatic netting and cancellation of offsetting contracts. Further, clearing derivatives through a CCP facilitate market liquidity. It allows, for instance, three different counterparties to exit the contracts without the need for an agreement by them and eliminating the credit risk of the offset contracts.

Duffie and Zhu (2011) provide a framework where the introduction of clearing for a single asset class, like CDS, could limit netting efficiencies increasing collateral demand and counterparty exposures at the same time. With a different parameterization of the model and different assumptions, Cont and Kokholm (2014) find that multi-asset class central clearing reduce interdealer exposures, but a single non-specialized clearing house can pose systemic risk issues. Acharya and Bisin (2014) show in their theoretical model that central clearing limits the excess risk-taking by the counterparties because of greater transparency and margin requirements. In the model of Biais et al. (2016) central clearing and an optimal margin design mitigate the moral hazard of excessive risk-taking and reduce counterparty risk. This prediction is consistent with Koeppl et al. (2012). Zawadowski (2013) shows that welfare improves when the OTC contracts are taxed to finance a bailout fund. Duffie et al. (2015) in their theoretical model calibrated with DTCC data find that collateral demand does not increase with mandatory central clearing. The model of Ghamami and Glasserman (2017) identify three main drivers to centrally clear a transaction when there is no clearing obligation, from the dealer's perspective. The first is the netting efficiency across asset classes; the second is the margin period of risk, i.e., the time between the counterparty's default and the closing of position; and the third is the size of the clearing members' contribution to the default fund.

The empirical literature on central clearing and CDS mainly uses DTCC data. Shachar (2012), for example, uses a sample of trades from 2007 to mid-2009 and finds that, as long as the cross exposure between dealers accumulates, the liquidity worsens. Loon and Zhong (2014), using a sample of 132 reference entities cleared by ICE and Markit quoted CDS spread, find that CDS spread increases after the introduction of central clearing, indicating 
that counterparty risk is priced. However, Du et al. (2016) using DTCC transaction data find the opposite results, i.e. cleared trades have lower spreads compared to uncleared trades. The latter result is consistent with Arora et al. (2012) who, with a proprietary dataset, show that the counterparty risk is priced, but is economically very small in magnitude. Siriwardane (2015) shows that the high concentration of the market around the dealers results in more volatile CDS premiums, while Mayordomo and Posch (2016) find that central clearing could lead to an increase in market activity especially for riskier dealers. ${ }^{7}$

Our paper is complementary to the above literature as it provides empirical evidence on the extent of central clearing and the underlying causes for the clearing decision. To our knowledge, this is the first academic paper that empirically investigates these issues.

\section{The Drivers of the Decision to Clear: Testable Hy- potheses}

Central clearing removes direct counterparty credit risk and replaces it with an exposure to a CCP. Under central clearing, a bilateral trade between two counterparties is replaced by two separate trades with the CCP. Since the CCP creates a legal separation between the original counterparties, she absorbs the risk associated with a counterparty default and protects the

\footnotetext{
${ }^{7}$ The literature on CCP and systemic risk is also large. The financial regulators identify the OTC derivatives market as a key source of instability, due to their interconnected nature of CDS counterparties that can potentially collapse in sequential failures of other counterparties (domino effect) starting from the failure of a single counterparty, as stressed by Pirrong (2011). For these reasons, an overarching aim of EMIR regulation is to mitigate the buildup and transmission of systemic risk in the derivative market. Given the large size of the net economic exposures between derivative dealers, the possibility of correlated counterparty failures is systemically important (see Getmansky et al. (2016)). Domanski et al. (2015) discuss how clearing houses could propagate systemic risk in financial markets through domino effects and deleveraging mechanisms. They suggest to increase the financial strength of both clearing members and CCPs, and develop robust risk management practices for the clearing houses. Lewandowska (2015) shows by using a simulation approach, that the mandatory clearing of all standardized OTC derivatives by a Central Clearing Counterparty would significantly decrease systemic risk only if the regulators ensure a sufficient number of clearing member and asset cleared. Amini et al. (2015) show how central clearing counterparties not only reduce the systemic risk but also increase the utility of banks through the netting benefits and the redistribution of default management resources within the financial market. Menkveld et al. (2015) analyze the effect of the central clearing counterparties on price stability by looking at the Nordic equity market, and find a volatility and volume reduction without any deterioration in market quality.
} 
non-defaulting counterparty. The effectiveness of a CCP is predicated on the requirement that clearing members post adequate capital and maintain sufficient collateral (margin) so that impacts of a defaulting clearing member can be mitigated. Moreover, these amounts should be sufficient so that the clearing house and its non-defaulting clearing members can absorb a clearing member default.

The SEC and the ESMA are both granted the power to determine which types of derivatives contracts are to be obligatory or voluntary centrally cleared. The eligibility depends on a number of specific factors, which include: 1) sufficient activity, trading liquidity, and adequate pricing data; 2) a well-functioning infrastructure to support clearing; 3) the opportunity for systemic risk mitigation; 4) the impact on competition; and 5) the opportunity to resolve failures of the clearing house or clearing members with reasonable legal certainty. ${ }^{8}$ On top of these factors identified for eligibility, the CCPs define other specific criteria for clearing eligibility of the different types of contracts. In Europe, beyond certain interest rate derivative classes, the clearing obligation concerns only untranched index CDS classes. Thus, the decision to clear single name CDS contracts is voluntary. ${ }^{9}$ This creates the conditions to study the factors that influence the decision to voluntarily clear a CDS single name contract. In this paper we investigate the following question: why only some sovereign CDS transactions currently eligible for multilateral clearing are being cleared while others are not? We analyze, from the clearing member perspective, what are the drivers of this decision by considering the following factors:

1. Margin costs: margin costs are related to both (i) the characteristics of the CDS contract and (ii) counterparty credit risk. Characteristics of the CDS contract, such as the liquidity and the risk of the underlying reference entity have a direct impact on the margin. Moreover, CCPs differentiate margins among counterparties having different ratings, i.e. having different CCR. We model CCR as a function of the stand-alone risk

\footnotetext{
${ }^{8}$ See Exchange Act Section 3C(b)(4)(B) and discussion in Porter (2015).

${ }^{9}$ See ESMA for further information regarding clearing obligation of derivative contracts available at https://www.esma.europa.eu/regulation/post-trading/ otc-derivatives-and-clearing-obligation
} 
of the counterparties. Therefore, the higher is the risk of the reference entity or the stand-alone CCR, the larger are the margin costs and the lower would be the incentive to clear.

2. Counterparty credit risk (CCR) capital requirements: Capital costs due to capital requirements are larger the higher is the CCR exposure. Since CCR capital requirements are lower for cleared contracts, higher is the CCR exposure larger would be the benefit in terms of capital requirements reduction if the contract has been cleared and therefore higher would be the incentive to clear. The ingredients are therefore the same as those of margin costs, but have the opposite effects on the incentives to clear. The reduction of CCR capital requirements through clearance is larger when (i) the CCR stand-alone is high and (ii) the exposure or the risk of the position is high.

3. Risk management: reduction of the clearing member CCP total margins exposure, which we model as a function of the size of the counterparties' outstanding exposures towards the CCP;

4. Transparency: differences in post-trade transparency between cleared and not cleared contracts might also provide lower incentives to clear because transparency might offer speculation opportunities to other traders. This is one of the main reasons why large size trades are usually performed OTC. We proxy the transparency incentives to not clear through the size of the contract.

These four factors are not independent. Clearly Factors 1 and 2 are largely related, and in most of the cases, they are the two faces of the same coin. In fact, on one side, clearance allows to reduce CCR capital requirements, but at the same time, the larger are the CCR exposures, the larger are the margin costs. Factor 3 includes a different perspective regarding margin costs, i.e. the fact that the cost of margins is based on the total net exposure the clearing member is having with the $\mathrm{CCP}$ and does not refer to just the single contract as in Factors 1 and 2 . 
Another factor that would be interesting to add to our analysis is the trade-off between multilateral netting through the CCP and bilateral netting between counterparties. Unfortunately, for the German and the French sovereign CDS contracts we cannot identify the counterparty of the CCP, and for the Italian CDS we were able to identify it only for a fraction of transactions. For this reason, we leave the investigation of this issue to further research.

We analyze the role of the above factors in the decision to clear, using a probit model. Specifically, we examine how clearing members react to the incentives and costs provided by central clearance. We test the following Hypothesis:

Hypothesis 1: Willingness to clear is larger if the contract is less liquid, has a large size and the reference entity is more risky.

The features of the contract can affect the clearing decision because margins and capital costs are largely related to the riskiness of the reference entity and the size of the contract. In particular, when the reference entity is risky or is becoming riskier, or when the size of the contract is large, margins would be high, both at the initial and maintenance level. For these reasons, the dealer has a lower incentive to clear. This refers to Factor 1 described above. Moreover, if the size of the contract is large, the dealer might prefer to avoid to clear it for transparency reasons. This also provides an incentive of not clearing the contract and refers to the Factor 4 reported above. However, reference entity risk and size of the contract affect CCR capital requirement costs as described in Factor 2 above. Therefore, the larger is the risk or the volume of the contract, the higher is the incentive to clear. To disentangle which of the factors prevails, an empirical analysis is required.

We formulate Hypothesis 1 as if CCR capital requirement reduction costs prevail as a reason to clear with respect to larger margin costs and transparency, i.e. Factor 2 versus Factors 1 and 4. If this Hypothesis were to be rejected empirically, margin costs and the need for opacity would be the main drivers in the decision to clear instead of the reduction of CCR capital requirements. The opposite is true if the Hypothesis 1 is not rejected. The 
empirical analysis sheds light on the relevance of margin and opacity versus CCR capital requirements costs.

The riskiness of the contract is proxied in our analysis by both (i) the Markit CDS quoted spread and (ii) the percentage change in the CDS quotes from the previous day. Additionally, we calculate a forecast of the volatility of the CDS using Exponential Weighted Moving Average Volatility according to RiskMetrics (1996) parameters. ${ }^{10}$

The liquidity of the reference entity might also play a relevant role in the decision to clear a contract. On the one side, more liquid contracts face lower margin requirements by the CCP (this refers to Factor 1). Moreover, the incentive to clear becomes larger when a certain reference entity in a given day is observing a significant amount of transactions because it would be easier to rebalance the CCP exposure (i.e. Factor 3). However, on the other side, if the increase of transactions is due to a large sovereign credit risk shock, like e.g. Brexit, market imbalance might generate difficulties to rebalance the CCP exposure (again Factor 3). In our empirical analysis we investigate these contrasting effects. We empirically proxy the liquidity of the contracts by looking at the number of daily trades for each reference entity.

Another important variable is the size of the transaction that also affects the decision to clear in two different ways. On the one hand, the larger is the transaction, the larger is the margin cost and therefore the incentive to clear would be lower (Factor 1). Moreover, a real-time reporting regime exists in the CDS market. However, this regime permits to report on a delayed basis the block trades, but at the same time, indirectly offers some speculation opportunities to other traders. Traders observing this real-time information flow may have the chance to front run the dealer that needs to unwind its exposure. This is the second reason of why large size contracts should reduce the probability to clear (Factor 4). However, on the other hand, large transactions generate a larger counterparty credit risk exposure (i.e.

\footnotetext{
${ }^{10}$ In particular, we use the logarithm of changes of the CDS Markit quotes and 150 daily observations to set the initial volatility and then we apply the recursive formula using a rolling window of 75 days, with a decay factor of 0.94 .
} 
Factor 2), and a larger benefit in terms of CCR capital requirements reduction if the contract were to be cleared. In our analysis, we investigate which of these opposing effects prevails. Therefore, the second Hypothesis we investigate is:

Hypothesis 2: Willingness to clear is larger if the transaction helps to manage margins, i.e. it decreases the amount of collateral to be posted because it reduces the exposure to the $C C P$.

To put the clearing decision into context, we consider the trade-offs associated with managing collateral on OTC transactions relative to those that are centrally cleared (factor 3 ). On the one hand, clearing members collect and post collateral with their bilateral counterparties on OTC transactions and most of the OTC non-cleared transactions are covered by bilateral master agreements that require the posting of variation margin and permit closeout netting in the event of a counterparty default for the sample period we considered. By contrast, when a dealer decides to centrally clear a trade, she is obligated to post initial and variation margins. ${ }^{11}$

The clearing decision depends on two components: (i) the net positions with the transacting counterparty and (ii) the net position with the CCP. By considering these aspects, a dealer would choose to clear a contract when the overall collateral commitment is smaller, that usually happens when the net exposure is reduced overall. Specifically, the dealers would face the problem to evaluate the margin costs between bilateral and multilateral netting as highlighted by Duffie and Zhu (2011) and Cont and Kokholm (2014). Generally, bilateral netting reduces the exposure to collateralize to a lesser extent than multilateral netting. However, in case of counterparty concentration, bilateral netting can also achieve significant reduction of exposures and bilateral arrangements may not require full collateralization. ${ }^{12}$

\footnotetext{
${ }^{11}$ In the meantime, the regulation has been changed from January 2017 onwards and now initial and variation margins are mandatory to collect also for the OTC derivative transactions (see the Commission Delegated Regulation (EU) 2016/2251 of October 4, 2016). However, our analysis covers transactions made in 2016, and therefore there is still a significant difference in margin requirements between cleared and non-cleared contracts for the sample considered.

${ }^{12}$ Unfortunately, bilateral netting situations cannot be analyzed in this paper due to the lack of reliable data. Therefore, we are aware that our analysis can provide only a partial and potentially biased view of the incentive to clear that derives from margin risk management purposes. However, it is the first attempt
} 
Another important aspect to consider is the ability to re-hypothecate collateral that can also have an impact on the decision to clear. Whereas dealers typically re-hypothecate collateral received on OTC derivatives trades, amounts received on margin accounts at the CCP are not typically re-hypothecated. Although CCPs will rebate back income earned on these assets, the relative marginal returns on the posted collateral can have an impact on the clearing decision. The trade-off between clearing a trade or remaining OTC is, in principle, related to the net position of the dealer with the $\mathrm{CCP}$ and the characteristics of the reference entity. Most clearing houses ${ }^{13}$ usually provide netting services, collateral management and calculation of margins at the portfolio level.

Since our database covers only part of the transactions of the clearing members (as we have focused on three sovereign CDS), and due to the fact that most of the clearing members are non-EU, we cannot rebuild their complete open position with the central counterparty across all asset classes and calculate exactly what is the amount of margin that a dealer is required to post (or save, if she trades in the opposite direction), as well as it is difficult to estimate the bilateral netting position for non-cleared transactions for all the traders.

Given the data available, the best that we can do is to calculate the daily open position of the dealer with the CCP as a proxy of the inventories and the additional costs of a new trade. CCP usually applies a short charge when a dealer is a net seller of protection. Given that both counterparties have to post margins, they can achieve sufficient economies of scale trying to have the smallest exposure with the CCP. Our Hypothesis is then related to the net position with the CCP: if a dealer is a net buyer, she prefers to clear the next trade only if it is going to take the opposite position (selling CDS) in order to reduce her position.

The same argument applies in the other case i.e. when a dealer is a net seller, she is willing to clear when the next transaction is a buy. However, it is fundamental to recall that both parties must agree on the decision to clear. Unfortunately, given the data we have, we cannot jointly test if the probability to clear is larger when both the traders have an incentive to perform this analysis not by simulation but through empirical evidence.

${ }^{13}$ See ICE (2015) for further details on margin calculation. 
to clear because of margin risk management reasons. We can only investigate individually whether, if the buyer is a net seller or the seller is a net buyer, the probability to clear is higher. In the case Hypothesis 2 is rejected we could not disentangle if this is because the incentive is not strong enough or the other trader disagrees to clear.

The third Hypothesis we study is:

Hypothesis 3: Willingness to clear is larger when the counterparty risk is larger.

The creditworthiness of a counterparty may also affect the demand for central clearing. Du et al. (2016) show that market participants manage counterparty risk by choosing counterparties that are less exposed to the wrong way risk and have better creditworthiness. In our analysis, we aim to verify whether the decision to clear is influenced by the riskiness of the counterparties stand-alone that provides two opposite incentives to clear: an increase of margin costs (factor 1) and a reduction of CCR capital requirements in case of clearance (factor 2).

We measure the CCR as a function of the stand-alone risk of the counterparties, proxied by the CDS spread of both seller and buyer. This variable could be considered both as (i) a proxy of the larger margins required by the CCP for riskier counterparties and (ii) the potential reduction of capital requirements, given that in Basel III regulation cleared contracts obtains lower risk weights for the counterparty credit risk capital requirements than non-cleared OTC contracts (Bank for International Settlements, 2012). The benefit of the reduction in capital requirements is larger for risky contracts, therefore, the probability to clear a contract should be larger if counterparties are more risky.

Other regulatory reforms may indirectly affect the clearing decision. For example, since the largest security swap dealers are affiliated with bank holding companies, swap dealers have been gradually flattening their trading books to comply with the Volcker Rule, according to Getmansky et al. (2016). This may be an endogenous response to prohibition on proprietary trading because non-zero net positions expose dealers to credit risk. If a position becomes large, regulators could view it as a proprietary trade rather than the outcome of 
legitimate market making. At the margin, the decision to comply with this regulation could have implications on the decision whether to transact with a specific counterparty or the CCP.

The Hypothesis described above are formulated from the perspective of a clearing member. They also apply to non-clearing members, but in this case, another relevant factor should be included: the cost faced by the non-clearing members to clear a contract through a broker (i.e. a clearing member). Unfortunately, we do not have information about these costs in our database, and therefore we do not include non-clearing members in our probit analysis. However, with our descriptive analysis, we provide some evidence on the actual clearance of contracts through non-clearing members, with the distinction of those subject to counterparty risk capital requirements and the others.

\section{Data description}

According to the Article 9 of the EMIR, the counterparties of a derivative contract have to report the details of the transaction, including modifications and cancellations to a trade repository, "no later than the working day following the conclusion, modification or termination of the contract.'The set of details shall be reported to a trade repository (TR) registered according to Article 55 title VI or recognized in accordance with Article 77 of the EMIR. Consequently, information of EU counterparties' trades is made available to ESMA and European Systemic Risk Board (ESRB), while country-specific information is made available to relevant domestic supervisory authorities. It is worth noting that the transaction is present in the dataset when at least one of the two counterparties is located in EU. If for instance, two US counterparties are trading a European sovereign CDS, this transaction is not reported in our database. If both or one of the two is EU domiciliated EU, then the details are reported in one of the EU registered trade repositories. According to the EMIR, the reporting obligation applies to the contracts that were entered before the August 16, 2012 
and are still outstanding, and the new contracts entered after August 16, 2012.

We use the EU wide dataset available at the ESRB. Abad et al. (2016) provide a comprehensive description of the data structure, as well as issues related to data quality. Hence, we borrow some of the insights provided in the paper to describe our sub-sample of the data. We focus our analysis on a subset of Sovereign CDS, where the reference entities are the Republic of Italy (Italy), the Federal Republic of Germany (Germany) and the French Republic (France). The entire database comprises all derivative classes (such as credit, commodity, equity, interest rate and foreign exchange). Six different TRs provide data to ESMA and ESRB. ${ }^{14}$ In general, the TRs provide two types of data: a mandatory report called "trade activity" that contains all the new trades, modifications and cancellations; and a second set of data, called "trade state" with the outstanding positions up to a certain date. We use the trade activity dataset for the daily analysis.

Regarding the sample that we extract from the trading activity raw data, we face a number of challenges that have been extensively described by Abad et al. (2016) and Fache Rousová et al. (2015). We briefly summarize the data cleaning procedure, referring to the aforementioned papers for more details.

In order to extract the correct reference entities for the German, French and Italian CDS contracts, we first retrieve all the unique underlying codes from the EMIR data. A formal distinction between sectors for the underlying is not present in the reporting mandatory fields, so we use different data providers to identify the reference entities. We use the ISIN codes of the sovereign bonds auctioned in the last ten years as a first source. We complement the auction data with the ECB-CSDB data, Datastream, the list of eligible ISINs from ICE Clear Credit, and the list of the RED6 code from Markit. Our broad list of underlying securities contains 8,858 unique identifiers, where roughly 2000 are related to sovereign debt and the remaining to public entities owned by the government that are also categorized as Sovereign by the data providers. These we ignore in the analysis. We then extract only the

\footnotetext{
${ }^{14}$ The six TR are CME, DTCC, ICE, KDPW, Regis-TR and UnaVista.
} 
trades related to these codes from the raw daily files, both for the OTC and the Exchange Traded Derivative (ETD) repositories. The initial database consists of 285,169 observations, with initial dates that span from 2004 to 2016 . Roughly $70 \%$ of the observations is from 2016 , where the quality and quantity of data has significantly improved. The EMIR regulation requires that both counterparties of the transaction have to report the trade to one of the authorized trade repository, i.e. this is the so-called "double-reporting" obligation. Thus, if a trade involves two EU counterparties, we find both records in the database, compared to the case where one counterparty is non-EU, where we find only one record. We unambiguously identify these two sets of transactions: the unique observations that cannot be matched, and the two observations reported by the EU counterparties and keep track of them. A specific flag, called "action type" allows us to partially track changes in the contract, features such as the notional amount, the upfront, the spread and so on. There are three timestamps reported for each transaction: the reporting timestamp, that refers to the moment when the counterparty communicates the trade to the TR; the execution timestamp, that indicates the moment when the transaction takes place; for some trades there is also the confirmation timestamp. We first drop the exact duplicates and the observations where the information regarding the spread (price), the notional and the upfront together are missing. Then, in order to be as conservative as possible, in the case of duplicate observations, we try to assess the quality of one of the two and possibly integrate the missing values of one with the other. For some trades, the CDS spread is directly reported, while for some others only the indication of the coupon is provided. ${ }^{15}$ However, we keep all the observations even if sometimes the price is not reported or not reliable. We prefer to avoid the use of the reported transaction price in our analysis because of lack of reliability or misreporting issues.

\footnotetext{
${ }^{15}$ When the contract is standardized the difference of cash called upfront is added. For the sovereign CDS, the fixed coupon is 25 or $100 \mathrm{bps}$.
} 


\section{Sovereign CDS Transactions}

As described in the previous section, the database used for our analysis includes all the sovereign single-name CDS transactions by EU financial institutions. Our analysis focuses on sovereign CDS, and in particular, the most traded European sovereign CDS: Italy (IT), France (FR) and Germany (GE). According to the globally aggregated transaction data provided by the DTCC on the TIW (Trade Information Warehouse) database, in the last quarter of 2016, the Italian CDS was the 5th most traded single name CDS by average daily notional amount, the French CDS was in the 20th position, and the German CDS in the 54th position. ${ }^{16}$

Table 1 describes the transactions reported in the EMIR database of the three sovereign CDS, and in particular, the gross and the net notional amounts and the number of counterparties, classified by the type of market participants. The counterparty categories reported in the database are "Banks", "Dealers", "Funds", "Other Institutions" and "Others". The category "Dealers" includes the group of the largest 16 dealers identified by the occasional paper Abad et al. (2016). ${ }^{17}$ The category "Other Institutions" includes Insurances, Pension funds, and Non-financial organizations. The category "Others" includes all the non-classifiable institutions. As Table 1 shows, the gross notional amount traded in 2016 and reported in the EMIR database is 797 billion of US dollars $(\mathrm{B} \$)$. The "Dealers" are the most active with $576 \mathrm{~B} \$$ of gross notional amount $(74.8 \%$ of the total gross notional amount) followed by the category "Banks" (96 B\$) and the category "Funds" (95B $\$$ ) with $12.01 \%$ and 11.92\%, respectively. The other two categories, "Other Institutions" and "Others", account for 7.72 $\mathrm{B} \$$ and $2.19 \mathrm{~B} \$$, respectively, that is $0.97 \%$ and $0.27 \%$ of the total gross notional. These numbers are in line with the evidence provided by Peltonen et al. (2014), and Abad et al. (2016), confirming that the CDS market is highly concentrated around a small number of

\footnotetext{
${ }^{16}$ Other European sovereigns that are in the 100 most actively traded single name CDS are Spain, Belgium and Portugal.

${ }^{17}$ The 16 largest dealers are Bank of America, Barclays, BNP Paribas, Citigroup, Crédit Agricole, Credit Suisse, Deutsche Bank, Goldman Sachs, HSBC, JPMorgan Chase, Morgan Stanley, Nomura, Royal Bank of Scotland, Société Générale, UBS, and Wells Fargo.
} 
counterparties. ${ }^{18}$ Our analysis confirms that the concentration of the market is a persistent feature. In fact, Abad et al. (2016) focuses on the CDS exposures at November 2nd, 2015; we instead look at all the transactions in 2016 and highlight the same feature.

Regarding the net notional amount, i.e. the difference between the amount bought and sold during 2016, panel A of Table 1 shows that the category "Dealers" presents a net exposure lower than the categories "Funds" and "Banks", $3.70 \mathrm{~B} \$$ versus $-7.22 \mathrm{~B} \$$ and 5.54 B\$, respectively. Moreover, "Dealers" in 2016 present a positive net amount: they are net buyers of CDS protections for the transactions done during the 2016. Instead, the net seller of protections are largely "Funds" and "Other Institutions" that includes Insurances and Pension funds. Among the 16 Dealers, the analysis shows that only 15 are active in the sovereign CDS market of Italy, France, and Germany. There are 33 "Banks" and 233 "Funds" in the sample. In addition, there are 40 other institutions like insurances and pension funds. Moreover, there are 123 institutions which type cannot be identified.

In the previous section, we highlight the peculiarities of clearing members versus nonclearing members, as well as the differences in the incentive to clear for the institutions that are subject to CCR capital requirements versus those that are not. For this reason, we report in Panel B of Table 1 the information of Panel A with the distinction between clearing member and all other institutions that are not clearing members, distinguishing among those that are subject to capital requirements and those that are not. The motivation behind this classification is that institutions subject to capital requirements could have advantages to clear derivatives transactions because of the reduction in the amount of capital requirements.

All dealers are clearing members in our dataset and the other 11 clearing members are all banks. ${ }^{19}$ Therefore, they are all subject to capital requirements and we avoid the distinction

\footnotetext{
${ }^{18}$ This evidence is also confirmed for the US corporate CDS market by Brunnermeier et al. (2013) and Getmansky et al. (2016).

${ }^{19}$ We define the set of clearing members according to the LEI (Legal Entity Identifier) membership list provided by ICE (www.theice.com). However, the same Global Ultimate Owner (GUO) could employ different LEI, which falls into the category of Dealer, Bank, or Fund. Table 1, Panel A, classify each market participant according to the LEI, while Table 1, Panel B takes into account the clearing membership dictated by ICE. For that reason, a LEI whose global ultimate owner is a Dealer or a Bank, falls into the category of Funds in Panel A, but is a Clearing Member on Panel B.
} 
on being subject to capital requirements or not for this category. Thus, we consider the following categories: clearing members; non-clearing members subject to capital requirements (CR); non-clearing members not subject to capital requirements (NCR); and not classifiable institutions (Others).

\section{INSERT TABLE 1 HERE}

Table 1 Panel B shows that clearing members are responsible for the largest fraction of contracts, roughly $96 \%$ in terms of gross notional amount, considering both cleared or not cleared contracts. The clearing members have a positive net notional amount of $9.3 \mathrm{~B} \$$ versus the negative total net notional amount of $-10.3 \mathrm{~B} \$$ for the non-clearing members (-2.2 $\mathrm{B} \$$ and $-8.1 \mathrm{~B} \$$, respectively for those subject to capital requirements and those not). Among the non-clearing members, the large fraction of the transactions is performed by traders not subject to capital requirements, $2.15 \%$ of the total gross notional amount that corresponds to $17.1 \mathrm{~B} \$$. This group of traders is instead the one having the largest net notional amount, $-8.1 \mathrm{~B} \$$, and are net sellers. This category is also the one with the largest number of counterparties, 266, versus non-clearing members subject to capital requirements that are 29 .

According to $\mathrm{ICE},{ }^{20}$ a single-name sovereign CDS reference entity can be cleared according to the following criteria:

- The contracts must be in USD and may be cleared to either ICE Clear Credit or ICE Clear Europe;

- For ICE Clear Credit, the Restructuring Clauses applicable are CR, CR14, MR, and MR14. For ICE Clear Europe, CR and CR14 ${ }^{21}$;

\footnotetext{
${ }^{20}$ see https://www. theice.com/clearing. The criteria of ICE are applied in the study to define eligibility for clearing.

${ }^{21}$ In addition, both ISDA 2003 and ISDA2014 Credit Derivatives Definitions can be cleared on both CCPs. The CDS for Italy can be cleared on both CCPs, while for German and Frech CDS only ICE Clear Europe accepts these contracts for clearing.
} 
- The fixed interest rate on the contract is either 25 or 100 basis points for the three reference entities selected;

- The tenor of the contract is less than 10 years;

- The reference Obligations are SNRFOR Tier (Senior Debt).

The BIS statistic ${ }^{22}$ reports that 1.7 trillions of dollars (T\$) of gross notional single name CDS on sovereign bond are outstanding at the end of the year 2016, and $551 \mathrm{~B} \$$ of this amount is cleared. Figure 1 shows the ratio between the gross notional amount of outstanding CDS contracts on sovereign bonds cleared over the total gross notional amount of outstanding CDS contracts on sovereign bonds. The ratio increases up to $32 \%$ for the single name sovereign CDS and up to 19\% for the multi-name index sovereign CDS at the end of 2016.

\section{INSERT FIGURE 1 HERE}

Moreover, the Financial Stability Board (2017) report indicates that clearing rates for the flow of new transactions in the OTC credit derivatives (both corporate and sovereign) as a whole are estimated at $37 \%$ in the EU and in index CDS at $80 \%$ in the US. In our analysis, we investigate the share of clearing vs. not clearing of the selected three sovereign CDS contracts. Differently from the statistics reported by the BIS and FSB, we also report the percentages of contracts that are eligible to clear but are not cleared, as well as those that are not eligible for clearance because they are not standard contracts accepted by the clearing houses. This information is crucial because it already provides an idea whether the contracts that are not cleared could not be cleared because they are not standard or because the traders decided not to clear.

Figure 2 reports the percentage of the gross amount cleared, the one eligible for clearing, and the percentage not eligible for clearing. The first bar of Figure 2 shows the percentages for all samples and indicates that the gross notional amount cleared is $48 \%$, the share of

\footnotetext{
${ }^{22}$ Data from BIS http://stats.bis.org/statx/srs/table/d10.4?p=20162\&c=
} 
contracts not cleared but eligible for clearing is $43 \%$, while the share of not clearable contracts is $9 \%$, respectively.

The most common reasons why a contract is not eligible for clearing are the following: the currency of the contract is Euro (89.21\%), the tenor is greater than 10 years $(10.41 \%)$, and the remaining $(0.38 \%)$ are securities (ISINs) not accepted by the clearing house for a specific reference entity. There is indeed a trend towards clearance as the clearing rate of $48 \%$ of the flow of new contracts in the sample is larger than the clearing rate of the stock of contracts reported by the BIS statistical reports (see Figure 1 at the end 2016). The percentage is also larger than the fraction of the flows of cleared contracts reported by Financial Stability Board (2017), indicating that sovereign CDS clearing is larger than corporate clearing. ${ }^{23}$

The second bar in Figure 2 shows the percentage of gross notional amount cleared, not cleared but eligible for clearing, and not clearable, for contracts where both counterparties are clearing members. The Figure shows that the fraction of cleared contracts among clearing members is larger than one half (53\%), that is a larger fraction of contracts has been cleared. The non-eligible to clear contracts are $8 \%$, therefore among the clearable contracts $58 \%$ of the gross notional amount has been cleared. This implies that there are indeed significant incentives for clearing members to clear even if clearance of single-names CDS contracts is not mandatory.

The last bar instead shows the percentages of cleared and non cleared contracts where at least one of the two counterparties is not a clearing member. In this case, the percentage of the notional amount cleared is close to zero (0.05\%), not comparable to the clearance fraction of clearing members $(53 \%)$. We argue that this is due to the fact that non-clearing members must go through a clearing member to clear the transaction (indirect clearing). We do not have information about these fees, but clearly if the fees requested by a broker to clear the contracts are relatively too high, the non-clearing members have no incentives

\footnotetext{
${ }^{23}$ The analysis might potentially overestimate the actual volume of the cleared transactions because sometimes it is impossible to match the two legs of the contract. For instance, we observe only one leg of the contract, when the contract is cleared, one of the counterparties is not EU regulated and the transaction is cleared through a US CCP.
} 
to clear. Instead, the fraction of transactions that are not eligible to clear because they are not standard, are about $20 \%$ of the gross notional amount. The difference is significant compared to the clearing members' transactions that have a percentage of $8 \%$ of non-eligible contracts.

Since one of the incentives to clear is the reduction of capital costs through lower capital requirements, Figure 3 reports the percentage of cleared versus clearable contracts distinguishing between non-clearing members that are either subject to capital requirements (CR) or not $(\mathrm{NCR})$.

\section{INSERT FIGURE 2 HERE}

Figure 3 shows that independently from capital requirement restrictions, the percentage of cleared notional amount is practically zero for non-clearing members subject to capital requirements and very low $(0.09 \%)$ for those not subject to capital requirements. This indicates that there are no incentives at all for non-clearing members to clear a contract, with no distinctions between institutions subject to capital requirements or not. Moreover, there is also a distinction between the two categories for a fraction of contracts that are eligible to clear. For non-clearing members subject to capital requirements, this fraction is $75 \%$, and for those non-clearing members not subject to capital requirements it is $85 \%$. This means that a larger fraction of contracts for non-clearing members subject to capital requirements are tailor-made contracts $(25 \%)$, potentially for their specific needs (in this category there are banks and insurances) or for the specific needs of banks' clients. Overall, this shows the dichotomy in the behavior of clearing members versus non-clearing members in their decision to clear (and incentives) as well as on the characteristics of the contracts that these different categories of counterparties are entering.

\section{INSERT FIGURE 3 HERE}

The histogram in Figure 4 shows the distribution of sovereign CDS contracts' tenor in our sample. The Figure shows that most of the activity is concentrated in the 5-year bucket, 
that covers around $30 \%$ of the total notional amount traded. More generally, $82 \%$ of the activity on CDS market in our sample is concentrated in contracts with maturity less then or equal to 5 years. For short-term contracts (tenor less of one year), the percentage is very small, around $2 \%$.

\section{INSERT FIGURE 4 HERE}

Finally, Figure 5 displays the share of the gross amount traded among the three reference entities considered: Germany, France and Italy. It shows that the mostly traded contract is the Italian one, $68 \%$ of the total amount traded in 2016, the second is France, $19 \%$ and the third is Germany, around 15\%. The ranking of the activity is in line with the market price of riskiness of these three sovereign CDS contracts. The heterogeneity among the different reference entities allows us to disentangle the role of the riskiness of the reference entity on the decision to clear.

INSERT FIGURE 5 HERE

\section{The Drivers of the Decision to Clear: Empirical Ev- idence}

What are the drivers of the decision to clear? We introduce several variables to test the hypotheses introduced in section 3, that are summarized in Table 2.

\section{INSERT TABLE 2 HERE}

We define several variables that are related to the characteristics of the contract and liquidity risk of the trade (Table 2 Panel A), the inventory position of the dealer with the CCP (Table 2 Panel B) and the riskiness of the two counterparties involved in a trade (Table 2 Panel A). In the same fashion, Table 3 provides the descriptive statistics for our sample.

INSERT TABLE 3 HERE 
The characteristic of the single contracts are summarized in Table 3 Panel A. The liquidity of the contract is captured by the variable "N. of Trades", that represents the number of daily trades in the sample for each of the three sovereign CDS conditional to observing at least one trade on that day (i.e. zero trades days are not considered in the statistics). The CDS contracts for the three sovereigns display a relatively similar average number of trades per day, ranging from 128 for Italy to 191 for Germany. However, we have far more observation for Italy than for Germany and France because we have less days with zero trades. The "Log Notional Amount" represents the log of the contracts' notional amount, also quite similar across reference entities. Using daily quotes from Markit, we introduce three variables that capture various aspects of the riskiness for each reference entity. The "CDS Volatility" is calculated as the Exponential Weighted Moving Average Volatility of the daily quotes. ${ }^{24}$ The three countries display a similar level of volatility in the sample. The "CDS Quote Spread" and " $\triangle$ CDS Spread" represents the level of the current CDS spread for each country, and the change in the spread from the previous day, respectively. The different level of riskiness of each country is clear from Table 3 Panel A. The lowest level of CDS spread belongs to Germany (average of $12 \mathrm{bps}$ ), while Italy displays a spread roughly ten times larger (average of $128 \mathrm{bps})$.

We also extract from the trade repository also the open positions of each trader with respect to the Clearing House, in order to calculate the daily net exposure. Thus, the net position with the $\mathrm{CCP}$ is defined as:

$$
\text { Position_wt_CCP } P_{i j t}=\frac{N e t \_N o t . \_w t \_C C P_{i j t}}{G . \_B o u g h t \_N o t . \_C l \cdot i j t+G . \_S o l d \_N o t . \_C l \cdot i j t} .
$$

where Net_Not._wt_CCP $i j t$ represents the net notional position with the CCP for the counterparty $i$, on reference entity $j$ and day $t$. The gross notional bought and sold are similarly defined. By construction, this ratio varies from -1 to +1 , where a negative number

\footnotetext{
${ }^{24}$ The Exponential Weighted Moving Average Volatility is calculated using a constant smoothing lambda parameter of 0.94 . The initial volatility is computed by considering a time interval of 150 observations with a rolling window of 75 observations according to Risk metrics.
} 
implies that the counterparty is a net seller of CDS protection. The statistics of Table 3 Panel B shows that for Germany and France most of the counterparties, either buyers or sellers, have an average positive position (net buyers of CDS protection). The opposite is true for Italy. Finally, as a proxy for the riskiness of each counterparty in a trade, we use the quoted 5 year CDS spread for both the buyer of CDS protection (Spread B_Dealer) and the seller of CDS protection (Spread $S \_$Dealer). From Table 3 Panel C we can see that the traders on average have a CDS spread around 100 bps for all the three contracts.

In order to formally test our three hypotheses, we estimate the following probit regressions separately for each sovereign CDS reference entity $k$ (Italy, Germany, and France):

$$
\operatorname{Pr}\left(Y_{t, k}=1\right)=\alpha_{0}+\beta \times X_{t, k}+\epsilon_{t, k}
$$

where $Y_{t, k}$ is equal to one if the transaction on the reference entity $k$ has been centrally cleared, and zero otherwise, also taking into account the eligibility rules of central clearing. The matrix $X$ contains a set of control variables, different for each Hypothesis tested, as well as a month fixed effect.

As presented in Section 5, our database shows that only transactions between two clearing members present a significant fraction of cleared contracts. Therefore, our analysis on the drivers for central clearing concentrates only on the transactions among clearing members and includes only the contracts that are eligible for central clearing. The inclusion of the contracts not eligible for clearing could potentially bias the results. Collateral to be posted or capital requirements do not influence the decision to clear since the characteristics of the contract preclude from the beginning this option.

\subsection{Hypothesis I: Contract and Liquidity Risk}

Hypothesis 1: Willingness to clear is larger if the contract is less liquid and when the reference entity is more risky.

As described in Table 2, Hypothesis 1 investigates the drivers of clearing looking at the contract characteristics, namely the CDS Spread, the change of the CDS spread, the CDS sovereign volatility of the reference entity, the trade size and the total number of daily trades 
for a specific reference entity.

Theoretically, some of these variables capture different dimensions that might have contrasting effects on the decision to clear. The empirical analysis allows us to disentangle which effect is prevailing. In particular, the size of the trade might have a positive impact on the willingness to clear, given the larger risk of the transaction. However, e.g. in order to avoid transparency, the trader might decide not to clear the contract. The number of daily trades for a specific reference entity might also increase the willingness to clear the contract because it indicates larger market liquidity, which usually lowers the margins. However, larger liquidity might reduce the willingness to clear the contract because of the counterparty credit risk, in this case, is lower since the contract would be easily matched. Again we have the trade-off between margin costs and CCR exposures. We have already explained that CCR exposures and capital requirements, as well as capital costs, are different dimensions of the same phenomena. In the discussion of results, when we refer to higher CCR exposures, we implicitly mean also higher capital requirements and higher capital costs. Volatility of the CDS market and the riskiness of the reference entity might be negatively correlated with the willingness to clear the contract because the margin requested by CCPs would be higher. However, the reference entity volatility might incentivize the decision to clear because the larger is the risk of the transaction, the larger is the CCR exposure, based on the fact that the higher is the volatility of the reference entity, the larger is the amount lost in case of default of one of the counterparties. Again, we allow the data to disentangle among these two potential effects that reject or confirm Hypothesis 1.

Table 4 reports the results of the multivariate regressions for Germany, France, and Italy, with and without month fixed effect.

\section{INSERT TABLE 4 HERE}

In line with Hypothesis 1, when the reference entity is risky, the probability to clear the contract is larger. The coefficient for the variable "CDS Quote Spread" is positive across countries, albeit statistically significant at the $1 \%$ level only for France and Italy. Higher potential margin costs do not prevent the counterparties to agree on clearance because CCR exposures are prevailing in the decision to clear. For Germany, the coefficients are not 
significant with and without fixed effect. This could be due to the fact that this variable is quite stable through time or the riskiness of Germany is so low that it is not having an impact both on margins costs and on CCR exposures. If we perform the same analysis including time fixed effects, the overall results are confirmed.

The second variable that we consider in our analysis is the change in the CDS spread level, " $\Delta$ CDS Spread." As the estimated coefficient shows, this variable has a negative and statistically significant coefficient for Germany and France, in line with the idea that an increase of the CDS spread of the reference entity increases margins, and therefore reduces the incentives to clear. For Italy, the sign of the estimated coefficient is positive, with stronger significance when including also the month fixed effect. This indicates that there are periods in the sample characterized by specific shocks that increase or reduce the probability to clear (like the outcome of the Brexit vote), potentially inducing a bias in the estimation if this aspect is not captured by time fixed effects. Overall, the results on the change in the CDS spread indicates that the potential increase of the risk of the reference entity induces to clear more in line with Hypothesis 1 and CCR exposure motivations, but only for the riskier country in the sample. For Germany and France, margin costs prevail on the CCR exposures on the decision to clear.

Considering the trade size ("Log Notional Amount"), the analysis shows that the larger is the volume of the transaction, the higher is the probability to clear. If the trader has to choose between disclosing the intention to take a large position on a contract or to incur in a large counterparty credit risk exposure, there is a preference for reducing the second one. This result is significant at the $1 \%$ level also including the time fixed effects analysis for France and Italy. However, for Germany, the estimated coefficient is not statistically significant, indicating that the CCR exposures are less relevant for the clearing decision.

The volatility of the quoted CDS spread, "CDS Volatility," has a negative sign for the three countries, indicating that the probability to clear is lower if the contract is more volatile, and therefore characterized by larger margins. However, the inclusion of the time fixed effect controls change the magnitude of the coefficient, and for Italy also the statistical significance of the coefficient. The econometric reasons for this result are the same as before: the inclusion of the time fixed effects controls for the variability of the clearance which is 
due to time series shocks. It seems, therefore, that for the Italian contract margin costs are not as relevant as the CCR exposures. Overall, according to the CDS volatility, we confirm that margin costs matter for the decision to clear a contract.

Finally, the number of transactions "N. of trades" shows a negative coefficient for all the reference entities. This indicates that the incentive to clear is lower when the contract is traded more. However, the coefficients for Germany and France are not statistically significant when including the time fixed effects to the regression. This indicates that there are clusters of periods when these contracts are either largely traded and others when their trading activity is low. This variability is captured by the time fixed effects and not by the cross-sectional variability generated by the different characteristics of the contracts between cleared and non-cleared transactions. Besides, the number of contracts written on sovereign CDS for Germany and France as reference entities are far lower than the contracts written on the Italian sovereign CDS (832 observation for German CDS, 1,713 observations for French CDS and 5,132 observations for Italian CDS).

In the appendix, Table 9, Table 10, and Table 11 report the probit results by regressing the dependent variable (clearing choice) with stand-alone explanatory variables, not controlling for month fixed effect. The analyses of the single variables are characterized by the omitted variable bias. Although these results do not contradict the analysis based on Table 4, they are less robust especially for contracts having Germany as reference entity, where only the variable "N of Trades" remains significant. In particular, "CDS Quote Spread" is still positive but only for France statistically significant; on the contrary, the coefficients are no longer significant for Germany and Italy. " $\triangle$ CDS Spread" is negative for France and positive for Italy and in both cases significant. These results are in line with the Table 4, and we can confirm that margin costs are found to be incentives impacting the decision to clear for France, and on the contrary, reference entity risk prevails for Italy. "Log Notional Amount" is positive and statistically significant for Italy and France indicating that the desire to hedge against a counterparty risk exposure overcomes the consequential cost of disclosing trading information. Although the sign of "CDS volatility" coefficient is coherent with the results of the Table 11 for all the reference entities, only for France it is significant, indicating that the margin is a relevant incentive for contracts having France as reference entity. Finally, 
the "N. of Trades" is negative and significant for all the three reference entities, confirming that the incentive to clear is less relevant when the contract is more liquid.

In general, our analysis confirms Hypothesis 1 for Italian CDS contracts: clearance is larger when the reference entity is riskier and therefore CCR exposures motivation for clearing prevails on the margin cost motivation for the decision to clear. For the German CDS, it seems that the incentives that prevail for clearing are those provided by margin costs. For France the results are mixed. It appears that both incentives, provided by margin costs and CCR exposures are relevant for the decision to clear French CDS. The mixed results justify the need to perform a separate analysis of the three contracts.

\subsection{Hypothesis 2: Position with the CCP}

Hypothesis 2: Willingness to clear is larger if the transaction helps to manage margins, i.e., it decreases the amount of collateral to be posted because it reduces the exposure to the CCP.

In this section, we consider the position of the single dealer vis-à-vis with the Central Counterparty. We model the decision to clear based on the intuition that, if a transaction helps to reduce the position with the CCP, dealers have the incentive to centrally clear, reducing the amount of collateral that has to be posted for this transaction.

In order to capture this behavior, we use the Position with the CCP (see equation 1) of the previous day for each counterparty, with respect to each reference entity (DE, FR, IT). We define the position as "flat" when the ratio is between plus and minus $5 \%$ of the total activity. A counterparty is a net buyer if this ratio is above $5 \%$ and net seller if the ratio is below minus 5\%. A number close to zero means that the counterparty is almost flat, while a number close to plus one or minus one displays a directional exposure with the CCP. We combine this information with the side of each trader (buyer or seller), and we isolate the two relevant cases: (i) when a buyer is a net seller, and (ii) when a seller is a net buyer. In principle, once a buyer is a net buyer, she does not have an incentive to go through the CCP, while when it is a net seller, clearing a transaction reduces her net exposure to the CCP and consequently the margins. The same argument also applies to the seller. Table 5 shows the results of the probit regressions on the position with the $\mathrm{CCP}$, for the buyer in Panel A and for the seller in Panel B. 


\section{INSERT TABLE 5 HERE}

For all the three countries, when the buyer is a net seller, and thus has the incentive to clear the contract, the probability that she would clear the contract is higher. The estimated coefficient is positive and significant at the $1 \%$ level. Adding time fixed effect leaves the sign of the coefficients invariant, but reduces the statistical significance for Germany. Table 5 panel $\mathrm{B}$ reports how the probability to clear is affected by the position of the seller with the CCP. In the univariate case, the coefficient is negative and significant, confirming that the probability to clear a transaction is lower when the seller has no incentive to do so. However, looking at the descriptive statistics in Table 3 Panel B, it appears that for the French and especially for the Italian contracts, the position of the single traders is on average flat. The incentives are higher when there is a strong directional position against the CCP. A closeto-flat position could not give enough benefit to offset the costs of clearing a transaction. In other words, we argue that the effect of the position with the CCP (the dummy for net buyer or net seller) is different based on the level of the position itself ("Exposure to the CCP"). For this reason, we introduce the interaction effect of the dummies with the level of the inventory.

We discuss only the coefficient of the interaction terms, since the interpretation of the "main-effects" coefficients in the regression with interaction terms is not straightforward. The work of Jaccard and Turrisi (2003) provides a detailed discussion of this issue. Table 6 shows the results of the probit regression with interaction terms for both buyer and seller.

\section{INSERT TABLE 6 HERE}

The probit regressions of Table 6 Panel A show that the interaction term is positive and highly significant for French and Italian CDS contracts: the larger is the position with the $\mathrm{CCP}$, the higher is the incentive to clear because this transaction might reduce the margins. This is not true for the contract written on Germany, where the coefficient is negative and significant only when including the time fixed effect. Therefore, for the buyer net seller for France and Italy, the results confirm the Hypothesis 2.

On the seller side, the results are confirmed only for the Italian contracts: when the seller is a net buyer, the incentive to clear this transaction is lower. For the German and the 
French CDS, the sign and significance are mixed. There are potential explanations for these heterogeneous results. The first is related to our proxy for the inventory position with the CCPs. Unfortunately, we cannot accurately reconstruct the seller position with the CCP. In fact, as in Du et al. (2016), the market participants avoid wrong-way risk, i.e., buying protection from a counterparty, whose credit risk is correlated with the underlying risk of the reference entity. Therefore, some of the sellers of sovereign CDS might not be European traders, and thus not obliged by the EMIR to report the transactions when the buyer is not European counterparty. Another potential explanation is that the buyer of the CDS is the one having the market power to impose clearance. If in the majority of the cases, the seller that is net buyer ends up to have as a counterparty a buyer that is not a net seller, the contract would not be cleared. On the opposite, if the seller is not a net buyer, but the buyer is a net seller the contract would be cleared. For these reasons, the results for the seller side must be interpreted with caution.

Unfortunately, our database does not allow us to identify, for a large fraction of the cleared transactions, who are the two parties. Therefore, we could not disentangle the cases when both counterparties have incentives to clear versus the case when only one of two has this incentive.

With the limitations due to the data availability, we could, in any case, conclude that the results in Table 5 and 6 , on the one side, confirm Hypothesis 2, but on the other side highlight the strategic behavior of the dealers in particular regarding their book conditions. If the buyer, as opposed to the seller, has strong incentive to maintain a directional position, they will try to avoid additional cost in terms of margin requirements and margin calls. If the buyer has a different incentive with respect to the seller to clear, in most of the cases, their incentives prevail in the decision to clear the contracts.

\subsection{Hypothesis 3: Counterparty Credit Risk}

Hypothesis 3: Willingness to clear is larger when the counterparty credit risk is larger.

In the last Hypothesis we test whether the riskiness of the counterparty, i.e., the CCR per se can influence the willingness to clear a contract, independently on the size of the contract and the riskiness of the reference entity. The proxy used for detecting the counterparty credit 
risk is the Dealer CDS spread with a tenor of 5 years.

\section{INSERT TABLE 7 HERE}

Table 7 shows the results of the probit estimation, including the CDS Spread of the buyer (Panel A) or the seller (Panel B). In all cases, also including time fixed effect, the coefficients of the CDS buyer or CDS seller are positive and largely statistically significant. Thus, the probability to clear the contract is larger when either the buyer or the seller presents a large credit default risk measured with the CDS spread.

The main differences across the countries are the magnitude of the coefficients. For the German CDS contracts, the coefficient of the buyer or the seller has a comparable size. For the French CDS contracts, the coefficient of the seller is almost twice as big as the one of the buyer, indicating larger probability to clear if the seller is risky, versus the case when the buyer is risky. The same conclusions hold for the Italian CDS contract. In particular, the univariate analysis shows that the coefficient of the CDS of the seller is positive and significant at the $1 \%$ level and is three times larger than the CDS of the buyer. This indicates that in both cases, the larger is the counterparty risk, the larger is the probability that the contract would be cleared. However, for the same level of counterparty risk, the incentive to clear is three times larger when the seller is risky than when the buyer is risky.

In summary, in all cases, the spread of the CDS dealers has a positive and significant relation with the probability to clear a contract, both the CCR of the buyer or the seller. Therefore, these empirical findings confirm the statement on Hypothesis 3.

For a fraction of the Italian CDS contracts cleared, we can identify the two counterparties that clear the contract with the CCP. Table 8 reports the results of the probit estimation including both buyer and seller CDS spread. We find that for both buyer and seller, counterparty credit risk matters. The result is robust to the inclusion of time FE. Therefore, Hypothesis 3 is largely confirmed.

INSERT TABLE 8 HERE 


\section{Conclusion}

This paper studies whether the post-crisis regulatory reforms developed by global standardsetting bodies have created appropriate incentives for different types of market participants to centrally clear OTC derivatives contracts. In particular, we analyze three main drivers for the decision to clear: 1) the liquidity and riskiness of the reference entity; 2) the credit risk of the counterparty; and 3) the clearing member's portfolio net exposure with the CCP.

We investigate empirically the relevance of these different drivers in the decision to clear by using a unique regulatory dataset: the confidential European trade repository data on single-name sovereign CDS transactions ruled by the EMIR. The database used for our analysis includes all derivatives transactions by EU financial institutions. However, our analysis focuses on transactions on sovereign CDS in 2016, and in particular, the most traded European sovereign CDS: Italy, France and Germany.

Our results demonstrate that the large majority of the transaction cleared are between CCP clearing members, while in our dataset there is almost no evidence of clearance of transactions by non-clearing members, independently whether they are subject to capital requirements or not. We also find that a large majority of the contracts could be cleared if the contract parties would agree on clearing these contracts. The fraction of non-eligible contracts for clearance is about $8 \%$ for the clearing members and between $15 \%$ and $25 \%$ for non-clearing members, depending on whether they are subject to capital requirements or not.

Focusing on contracts that are eligible for clearing, we investigate factors that drive clearing members' decision to clear. First, we find that both capital costs and margin costs are relevant for the decision to clear with some differences among the three sovereign CDS contracts. For the Italian sovereign CDS, the counterparty credit risk exposure is more relevant than the margin costs in the decision to clear, while for the German sovereign CDS contracts margin costs are the most important. Instead, the French sovereign CDS contract it is difficult to disentangle which of the two main drivers prevails. Second, we find that when a net seller of a specific sovereign CDS buys an additional contract, its propensity to clear increases. We find this for all the three reference entities, indicating that portfolio 
positions with the CCP also matter on the decision to clear the single contracts. Finally, we find that the counterparty credit risk alone is an important incentive to clear a contract, as this factor is significant for all analyzed reference entities.

Our study has several potential policy implications. First, it shows that the indirect clearing of non-clearing members, independently whether they are subject to capital requirements, is very low. Thus, regulators should further investigate reasons for this, and better understand the cost factors and other potential obstacles for client clearing. Second, our results show that factors impacting the incentives for central clearing are not the same for all analyzed CDS reference entities. Therefore, further detailed analysis of the role of the different reference entity characteristics should be considered. Finally, our analysis shows that the decision to clear is also related to net exposure with the $\mathrm{CCP}$, in addition to the characteristics of the contract and the counterparty credit risk. This should give incentives for cross-asset clearance, which implications should be further analyzed. 


\section{References}

Abad, J., Aldasoro, I., Aymanns, C., D’Errico, M., Rousová, L. F., et al. (2016). Shedding light on dark markets: First insights from the new EU-wide OTC derivatives dataset. European Systemic Risk Board Occasional Paper, 11.

Acharya, V. and Bisin, A. (2014). Counterparty risk externality: Centralized versus overthe-counter markets. Journal of Economic Theory, 149:153-182.

Amini, H., Filipović, D., and Minca, A. (2015). Systemic risk and central clearing counterparty design. Working Paper. Available at www.ssrn.com.

Arora, N., Gandhi, P., and Longstaff, F. A. (2012). Counterparty credit risk and the credit default swap market. Journal of Financial Economics, 103(2):280-293.

Bank for International Settlements (2012). Capital requirements for bank exposures to central counterparties. Available at www.bis.org.

Bank for International Settlements (2014). Regulatory reform of over-the-counter derivatives: an assessment of incentives to clear centrally. Available at www.bis.org.

Biais, B., Heider, F., and Hoerova, M. (2016). Risk-sharing or Risk-taking? Counterparty Risk, Incentives, and Margins. The Journal of Finance, 71(4):1669-1698.

Bliss, R. R. and Steigerwald, R. S. (2006). Derivatives clearing and settlement: A comparison of central counterparties and alternative structures. Financial Analysts Journal, (4):62-82.

Brunnermeier, M., Clerc, L., Scheicher, M., et al. (2013). Assessing contagion risks in the cds market. European Systemic Risk Board Occasional Paper, 4.

Cont, R. and Kokholm, T. (2014). Central clearing of OTC derivatives: bilateral vs multilateral netting. Statistics and Risk Modeling, 31(1):3-22.

Domanski, D., Gambacorta, L., and Picillo, C. (2015). Central clearing: trends and current issues. BIS Quarterly Review.

Du, W., Gadgil, S., Gordy, M. B., and Vega, C. (2016). Counterparty risk and counterparty choice in the credit default swap market. Working Paper.

Duffie, D., Scheicher, M., and Vuillemey, G. (2015). Central clearing and collateral demand. Journal of Financial Economics, 116(2):237-256.

Duffie, D. and Zhu, H. (2011). Does a central clearing counterparty reduce counterparty risk? The Review of Asset Pricing Studies, 1(1):4-95.

Fache Rousová, L., Osiewicz, M., and Skrzypczynński, G. (2015). Reporting of derivatives transactions in Europe: Exploring the potential of EMIR micro data against the challenges of aggregation across six trade repositories. Prepared for the 2015 ISI World Statistics Congress in Rio de Janeiro. Available at: http://goo.gl/NSUhgg. 
Financial Stability Board (2017). Review of OTC derivatives market reforms: Effectiveness and broader effects of the reforms. Available at www.fsb.org.

Getmansky, M., Girardi, G., and Lewis, C. (2016). Interconnectedness in the CDS market. Financial Analysts Journal, 72(4):62-82.

Ghamami, S. and Glasserman, P. (2017). Does OTC derivatives reform incentivize central clearing? Journal of Financial Intermediation, 32:76-87.

Jaccard, J. and Turrisi, R. (2003). Interaction effects in multiple regression. Number 72. Sage.

Koeppl, T., Monnet, C., and Temzelides, T. (2012). Optimal clearing arrangements for financial trades. Journal of Financial Economics, 103(1):189-203.

Lewandowska, O. (2015). OTC clearing arrangements for bank systemic risk regulation: a simulation approach. Journal of Money, Credit and Banking, 47(6):1177-1203.

Loon, Y. C. and Zhong, Z. K. (2014). The impact of central clearing on counterparty risk, liquidity, and trading: Evidence from the credit default swap market. Journal of Financial Economics, 112(1):91-115.

Mayordomo, S. and Posch, P. N. (2016). Does central clearing benefit risky dealers? Journal of International Financial Markets, Institutions and Money, 42:91-100.

Menkveld, A. J., Pagnotta, E., and Zoican, M. A. (2015). Does central clearing affect price stability? Evidence from Nordic equity markets. Working Paper, available at www.ssrn.com.

Peltonen, T. A., Scheicher, M., and Vuillemey, G. (2014). The network structure of the CDS market and its determinants. Journal of Financial Stability, 13:118-133.

Pirrong, C. (2011). The economics of central clearing: theory and practice. New York: International Swaps and Derivatives Association.

Porter, B. (2015). Single-name corporate credit default swaps: Background data analysis on voluntary clearing activity. U.S. Security and Exchange Commission White papers.

Shachar, O. (2012). Exposing the exposed: Intermediation capacity in the credit default swap market. Federal Researve Bank of New York Working paper.

Siriwardane, E. (2015). Concentrated capital losses and the pricing of corporate credit risk. OFR Working Paper, available at www.financialresearch.gov.

Zawadowski, A. (2013). Entangled financial systems. The Review of Financial Studies, 26(5):1291-1323. 


\section{Figures}

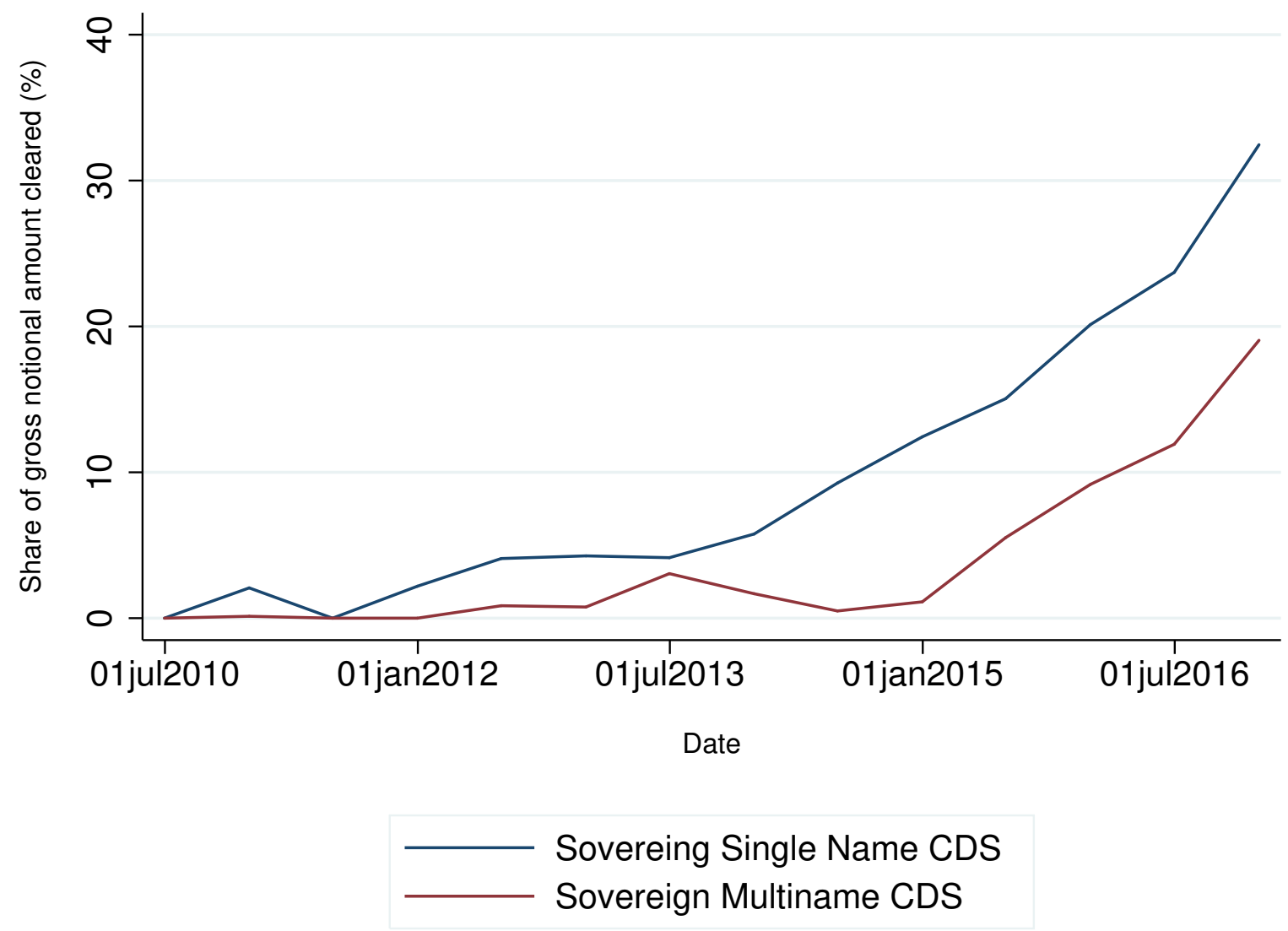

Figure 1: Share of cleared sovereign CDS contracts of gross notional amount

This figure shows the ratio between the gross notional cleared and the total gross notional amount for single name sovereign CDS and multi-name sovereign CDS contracts. The ratio is calculated starting from the semi-annual open positions with a sample from June 2010 to December 2016. The source of data is the BIS over-the-counter (OTC) derivatives statistics database, available at http://stats.bis.org/statx/srs/table/d10.4?p=20162\&c= 


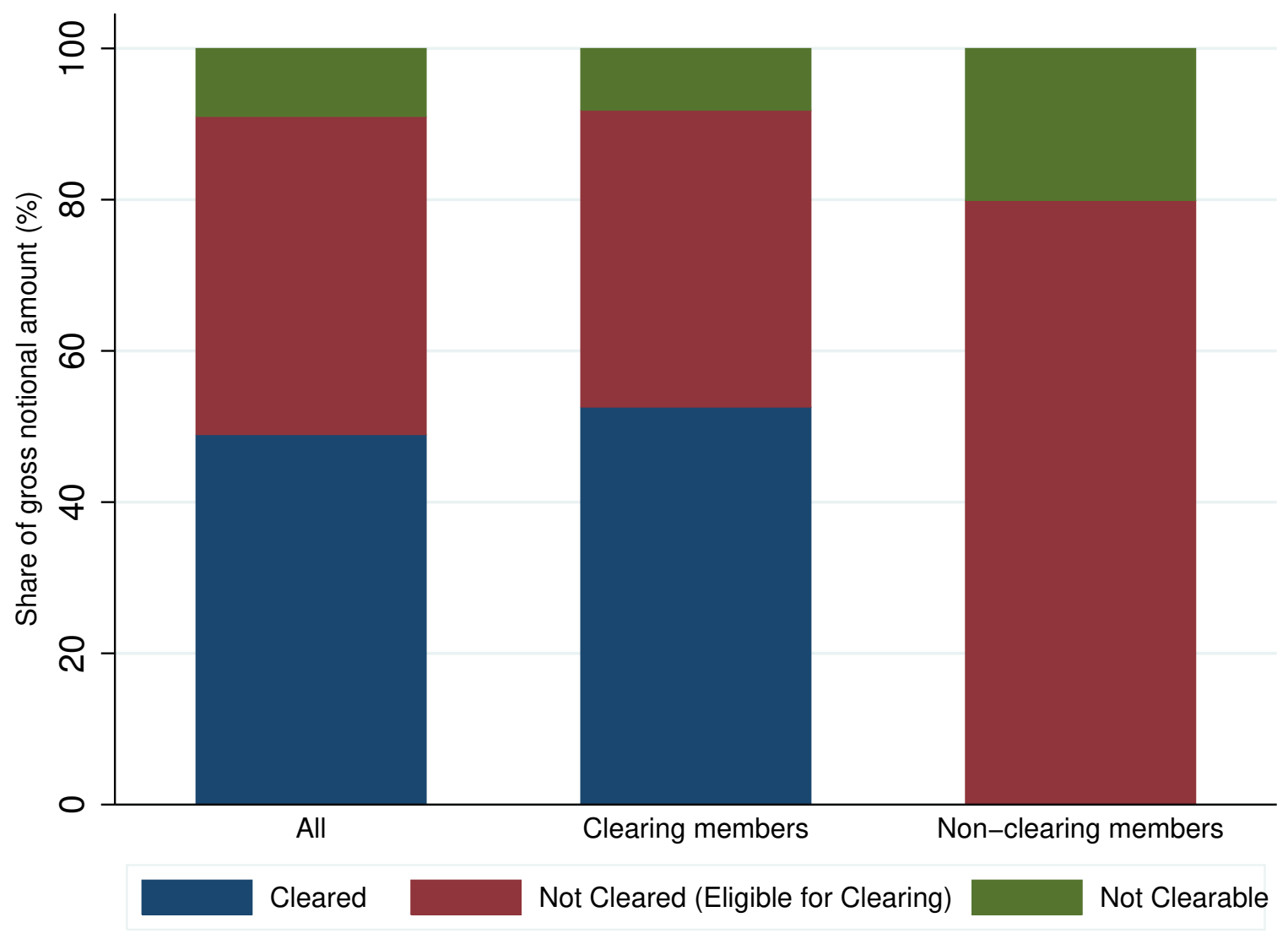

\section{Figure 2: Clearing of sovereign CDS contracts by counterparty type}

This figure shows the share of gross notional amount traded in our sample, classifying each trade under the following categories: cleared, not cleared, and not eligible for clearing, as described in Section 5. The first bar includes all contracts traded in our sample, the second bar includes only the contracts where both of the counterparties are clearing members, while the third bar includes the contracts where one of the two counterparties is a clearing member. The sample is composed of single-name sovereign CDS contracts written on Italy, Germany and France as a reference entity in 2016. Data comes from trade repositories under the the EMIR reporting requirement. 


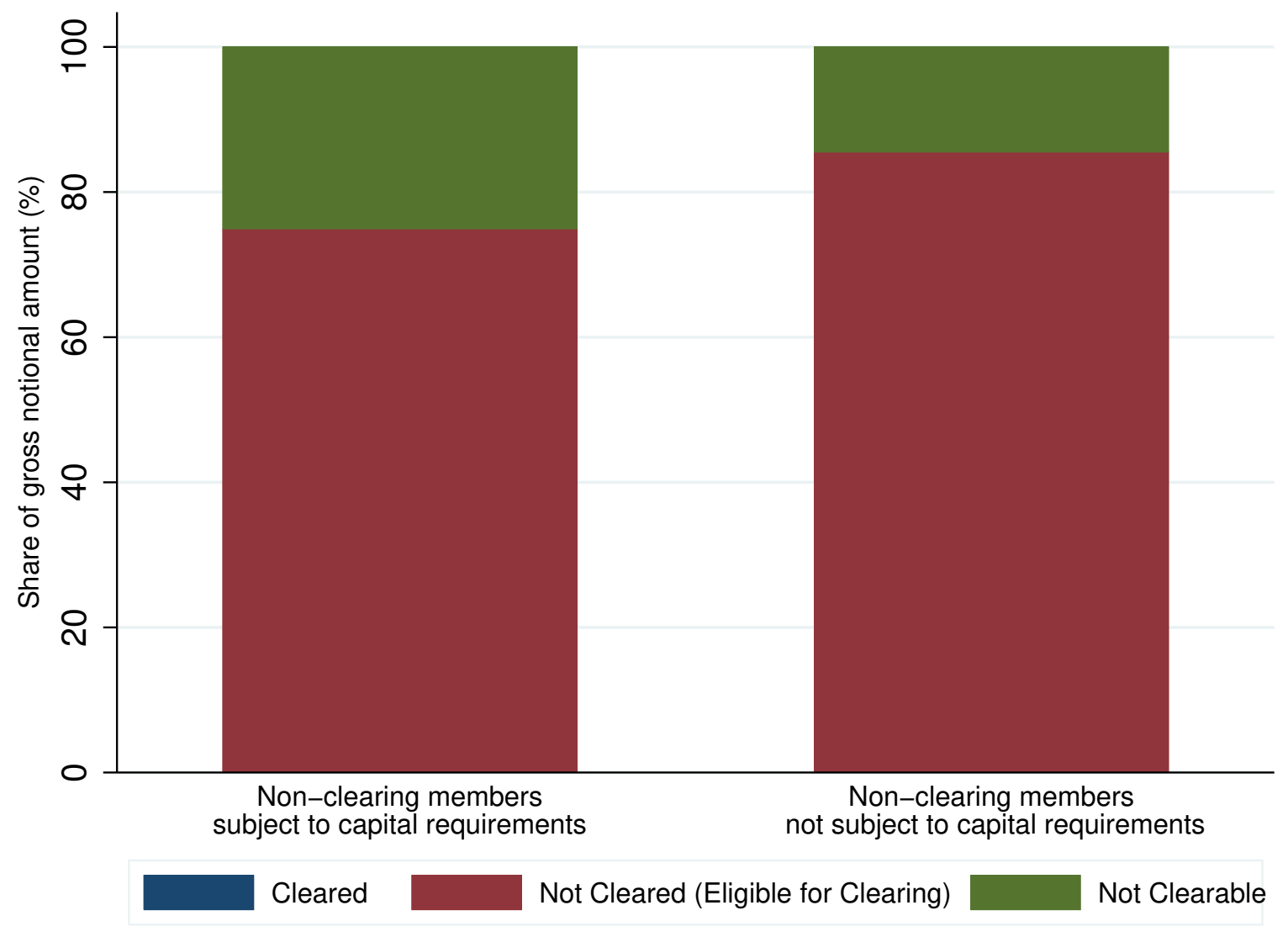

\section{Figure 3: Central Clearing Eligibility, Client Clearing and Capital Requirements}

This figure shows the share of gross notional amount traded in our sample, including only the trades where only one of the two counterparties is a clearing member. We classify each trade under the the following categories: cleared, not cleared, and not eligible for clearing, as described in Section 5. The first bar includes all the contracts where the non-clearing member is subject to capital requirements. The second bar includes all the contracts where the non-clearing member is not subject to capital requirements. The sample is composed of single-name sovereign CDS contracts written on Italy, Germany and France as a reference entity in 2016. Data comes from trade repositories under the the EMIR reporting requirement. 


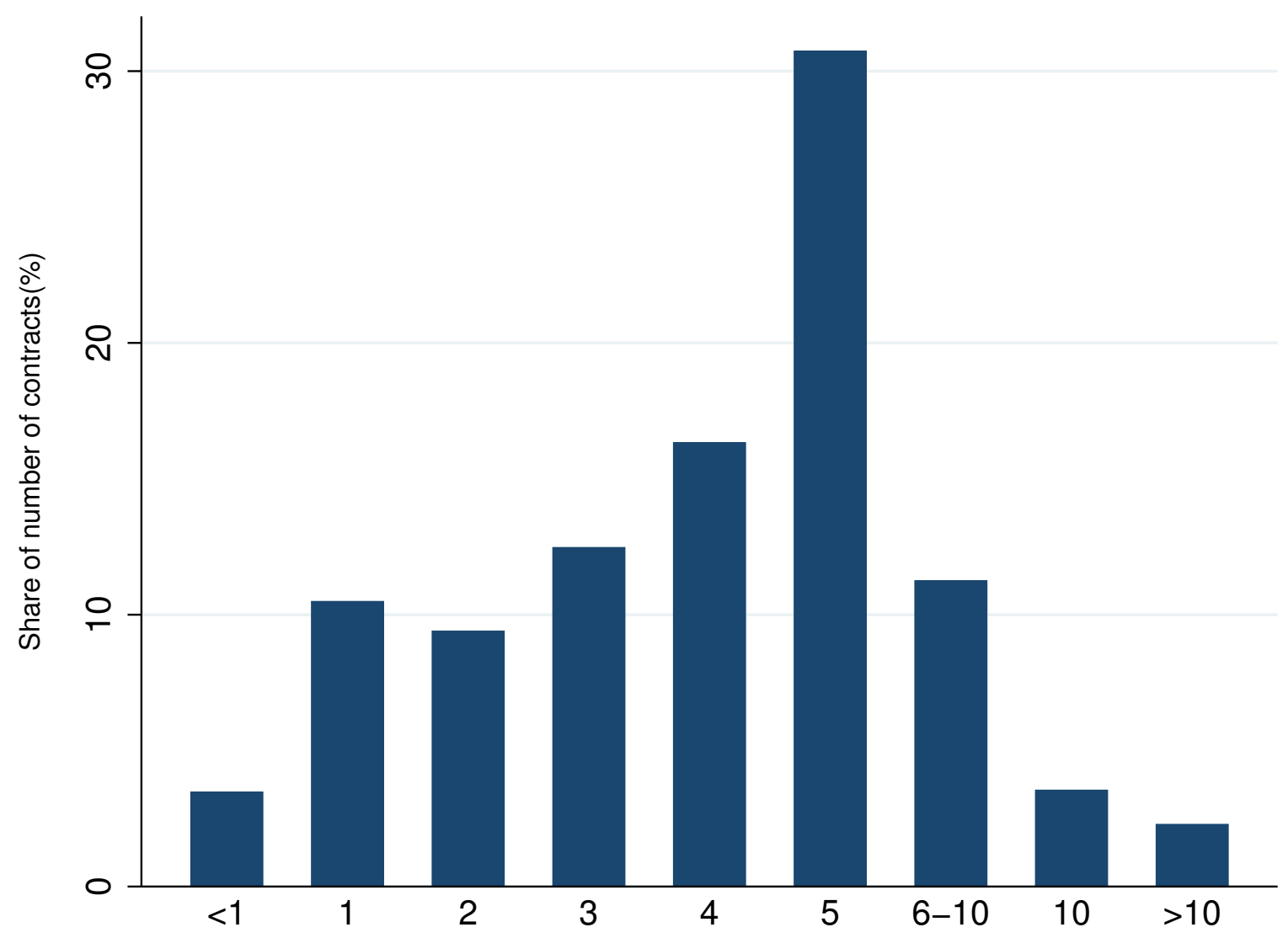

Figure 4: Distribution of sovereign CDS contracts' tenor

This figure shows the relative frequency of CDS transactions, grouped by buckets of tenors. The sample is composed of single-name sovereign CDS contracts written on Italy, Germany and France as a reference entity in 2016. Data comes from trade repositories under the the EMIR reporting requirement. 


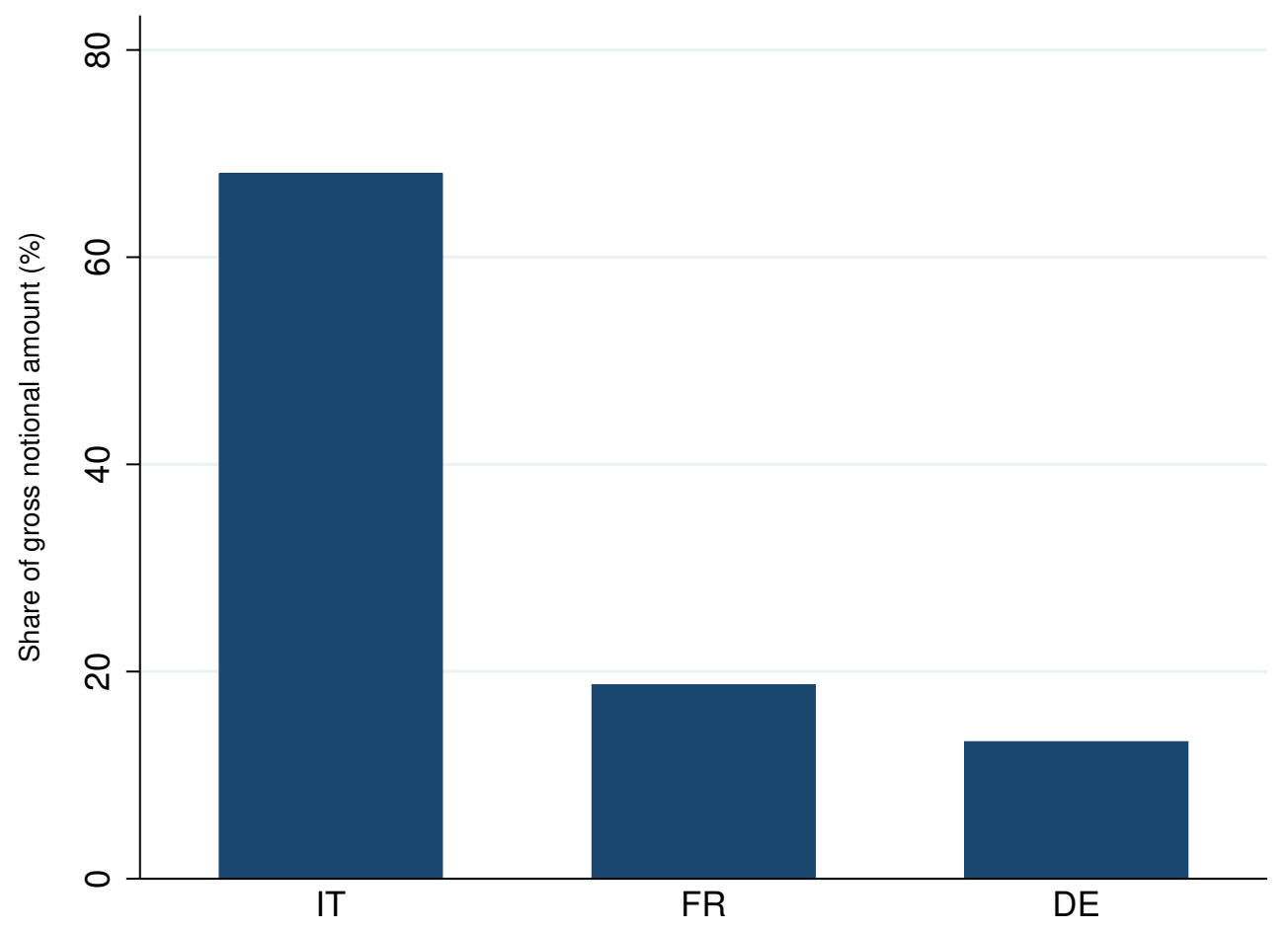

Figure 5: Share of the gross notional amount traded

This figure shows the share of the total gross notional amount traded for each of the three sovereign CDS reference entity included in our sample. The sample is composed of single-name sovereign CDS contracts written on Italy, Germany and France as a reference entity in 2016. Data comes from trade repositories under the the EMIR reporting requirement. 


\section{Tables}

Table 1: Notional amounts and number of counterparties by type of market participant

For both panels, we report the gross notional amount both in US dollar billion and in percentage, the net notional amount, and the number of counterparties for each market participant category. Panel A shows the data by the market participant type. The category "Other Institutions" includes Insurances, Pension, and Not financial organizations. The category "Others" contains all the others not classifiable institutions. Panel B shows the data by institutions grouped in categories: "Non-Clearing Members (CR)" are the non-clearing members institutions subject to capital requirements", "Non-Clearing Members (NCR)" are the non-clearing members institutions not subject to capital requirements, while "Others" holds all the other non-classifiable institutions.

Panel A

\begin{tabular}{ccccc}
\hline Market Participants & $\begin{array}{c}\text { Gross } \\
\text { Notional } \\
\text { Amount (B) }\end{array}$ & $\begin{array}{c}\text { Gross } \\
\text { Notional } \\
\text { Amount (\%) }\end{array}$ & $\begin{array}{c}\text { Net Notional } \\
\text { Amount (B\$) }\end{array}$ & $\begin{array}{c}\text { Number of } \\
\text { Counterparties }\end{array}$ \\
Banks & 95.8 & $12.0 \%$ & 5.5 & 33 \\
Dealers & 596.6 & $74.8 \%$ & 3.7 & 15 \\
Funds & 95.1 & $11.9 \%$ & -7.2 & 233 \\
Other Inst. & 7.7 & $1.0 \%$ & -2.1 & 40 \\
Others & 2.6 & $0.3 \%$ & 0.0 & 123
\end{tabular}

Panel B

\begin{tabular}{ccccc}
\hline Market Participants & $\begin{array}{c}\text { Gross } \\
\text { Notional } \\
\text { Amount (B\$) }\end{array}$ & $\begin{array}{c}\text { Gross } \\
\text { Notional } \\
\text { Amount (\%) }\end{array}$ & $\begin{array}{c}\text { Net Notional } \\
\text { Amount (B\$) }\end{array}$ & $\begin{array}{c}\text { Number of } \\
\text { Counterparties }\end{array}$ \\
Clearing Members & 769.1 & $96.5 \%$ & 9.7 & 26 \\
Non-Clearing Members (CR) & 8.5 & $1.1 \%$ & -2.2 & 29 \\
Non-Clearing Members (NCR) & 17.1 & $2.1 \%$ & -8.1 & 266 \\
Others & 2.6 & $0.3 \%$ & -0.3 & 123
\end{tabular}




\section{Table 2: Description of variables}

The table shows the explanatory variables used for testing the following three Hypothesis: 1) Contract and Liquidity Risk (Panel A), 2) Position with the CCP (Panel B) and 3) Counterparty Credit Risk (Panel C). The table reports the variables considered, their description and data source.

Panel A Hypothesis 1: Contract and Liquidity Risk

\begin{tabular}{|c|c|c|}
\hline Variable & Description & Data source \\
\hline N. of Trades & $\begin{array}{c}\text { Daily trades: Number of daily trades of a particular } \\
\text { reference entity }\end{array}$ & EMIR \\
\hline Log Notional Amount & $\begin{array}{c}\text { Trade Volume : The logarithm of the contracts' } \\
\text { notional amount }\end{array}$ & EMIR \\
\hline CDS Volatility & $\begin{array}{l}\text { Exponential Weighted Moving Average Volatility of the } \\
\text { CDS spread Market }\end{array}$ & Markit \\
\hline CDS Quote Spread & CDS Quote Spread of a particular reference entity & Markit \\
\hline$\Delta$ CDS Spread & CDS Spread of a particular reference entity change & Markit \\
\hline \multicolumn{3}{|c|}{ Panel B Hypothesis 2 : Position with the CCP } \\
\hline Variable & Description & Data source \\
\hline $\begin{array}{l}\text { Seller is net buyer } \\
\text { with CCP (Dummy) }\end{array}$ & $\begin{array}{l}\text { Net buyer sells protection: Trades where the Seller is a } \\
\text { net buyer }\end{array}$ & EMIR \\
\hline $\begin{array}{l}\text { Buyer is net seller } \\
\text { with CCP (Dummy) }\end{array}$ & $\begin{array}{c}\text { Net seller buys protection: Trades where the Buyer is a } \\
\text { net seller }\end{array}$ & EMIR \\
\hline $\begin{array}{l}\text { Buyer's exposure to } \\
\text { the CCP }\end{array}$ & $\begin{array}{c}\text { Inventories of the Buyer : Net open position with the } \\
\text { CCP at a reference entity level }\end{array}$ & EMIR \\
\hline $\begin{array}{l}\text { Seller's exposure to } \\
\text { the CCP }\end{array}$ & $\begin{array}{l}\text { Inventories of the Seller: Net open position with the } \\
\text { CCP at a reference entity level }\end{array}$ & EMIR \\
\hline \multicolumn{3}{|c|}{ Panel C HP 3 : Counterparty Credit Risk } \\
\hline Variable & Description & Data source \\
\hline Spread Buyer - 5Y & Buyer CDS spread with Tenor 5 years & Markit \\
\hline Spread Seller - 5Y & Seller CDS spread with Tenor 5 years & Markit \\
\hline
\end{tabular}




\section{Table 3: Descriptive statistics}

The table shows descriptive statistics for the explanatory variables used for testing the following three hypotheses: 1) Contract and Liquidity Risk (Panel A), 2) Position with the CCP (Panel B) and 3) Counterparty Credit Risk (Panel C).

\begin{tabular}{|c|c|c|c|c|c|c|c|c|c|}
\hline \multicolumn{10}{|c|}{ Panel A } \\
\hline \multirow[b]{2}{*}{ Variables } & \multicolumn{3}{|c|}{$\mathrm{DE}$} & \multicolumn{3}{|c|}{ FR } & \multicolumn{3}{|c|}{ IT } \\
\hline & N. Obs. & Mean & S.dev. & N. Obs. & Mean & S.dev. & N. Obs. & Mean & S.dev. \\
\hline N. of trades & 1363 & 191.511 & 192.203 & 2748 & 173.081 & 156.305 & 8289 & 128.257 & 138.735 \\
\hline Log Notional Amount & 1332 & 15.838 & 2.445 & 2666 & 15.432 & 2.297 & 8053 & 16.112 & 1.882 \\
\hline CDS Volatility & 1147 & 0.031 & 0.017 & 2360 & 0.027 & 0.016 & 7391 & 0.028 & 0.012 \\
\hline CDS Quote Spread & 1336 & 12.565 & 10.093 & 2705 & 30.107 & 16.128 & 8219 & 128.765 & 41.065 \\
\hline$\Delta$ CDS Spread & 1336 & 0.036 & 0.659 & 2705 & 0.231 & 1.172 & 8219 & 0.172 & 4.650 \\
\hline
\end{tabular}

Panel B

\begin{tabular}{|c|c|c|c|c|c|c|c|c|c|}
\hline \multirow[b]{2}{*}{ Variables } & \multicolumn{3}{|c|}{ DE } & \multicolumn{3}{|c|}{ FR } & \multicolumn{3}{|c|}{ IT } \\
\hline & N. Obs. & Mean & S.dev. & N. Obs. & Mean & S.dev. & N. Obs. & Mean & S.dev. \\
\hline $\begin{array}{c}\text { Buyer's exposure to } \\
\text { the CCP }\end{array}$ & 231 & 0.273 & 0.439 & 674 & 0.107 & 0.300 & 2947 & -0.064 & 0.310 \\
\hline $\begin{array}{c}\text { Seller's exposure to } \\
\text { the CCP }\end{array}$ & 207 & 0.257 & 0.424 & 521 & 0.053 & 0.393 & 2653 & -0.089 & 0.323 \\
\hline
\end{tabular}

Panel C

\begin{tabular}{|c|c|c|c|c|c|c|c|c|c|}
\hline \multirow[b]{2}{*}{ Variables } & \multicolumn{3}{|c|}{$\mathrm{DE}$} & \multicolumn{3}{|c|}{ FR } & \multicolumn{3}{|c|}{ IT } \\
\hline & N. Obs. & Mean & S.dev. & N. Obs. & Mean & S.dev. & N. Obs. & Mean & S.dev. \\
\hline Spread Buyer - 5Y & 877 & 99.707 & 18.813 & 2120 & 99.887 & 16.098 & 5838 & 97.589 & 24.684 \\
\hline Spread Seller - 5Y & 895 & 99.278 & 18.501 & 1940 & 101.141 & 21.223 & 4997 & 99.385 & 26.437 \\
\hline
\end{tabular}


Table 4: Hypothesis 1: Contract and Liquidity Risk estimations for sovereign CDS This table shows the estimated probit model results for contracts having Germany France and Italy as reference entity, and where both of the counterparties are clearing members $(\mathrm{CM})$. The dependent variable is a dummy variable equal to one when the contract is cleared. The explanatory variables used are: the CDS spread of the reference entity (CDS Quote Spread), the first difference of the CDS spread ( $\triangle$ CDS Spread), the logarithm of the Notional amount of the contract (Log Notional Amount), the exponential weighted moving average of the CDS returns of the reference entity (CDS Volatility), the number of the daily transactions (N. of trades). In the model presented in the last column of the table, controls for month fixed effects are included.

\begin{tabular}{|c|c|c|c|c|c|c|}
\hline \multirow[b]{2}{*}{ Models } & \multicolumn{2}{|c|}{$\mathrm{DE}$} & \multicolumn{2}{|c|}{ FR } & \multicolumn{2}{|c|}{ IT } \\
\hline & $(1)$ & $(2)$ & $(3)$ & $(4)$ & (5) & $(6)$ \\
\hline \multirow[t]{2}{*}{ CDS Quote Spread } & 0.0008 & 0.0006 & $0.0067^{* * *}$ & $0.0098^{* * *}$ & $0.0016^{* * *}$ & $0.0028^{* * *}$ \\
\hline & $(0.0048)$ & $(0.0054)$ & $(0.0022)$ & $(0.0023)$ & $(0.0004)$ & $(0.0005)$ \\
\hline \multirow[t]{2}{*}{$\Delta$ CDS Spread } & $-0.163^{*}$ & $-0.270^{* *}$ & $-0.125^{* * *}$ & $-0.122^{* *}$ & $0.0074^{*}$ & $0.0188^{* * *}$ \\
\hline & $(0.0964)$ & $(0.127)$ & $(0.0469)$ & $(0.0579)$ & $(0.0040)$ & $(0.0045)$ \\
\hline \multirow[t]{2}{*}{ CDS Volatility } & $-12.72^{* * *}$ & $-34.86^{* * *}$ & $-14.09^{* * *}$ & $-6.873^{* *}$ & -0.473 & $5.358^{* *}$ \\
\hline & $(3.496)$ & $(8.142)$ & $(2.753)$ & $(3.398)$ & $(1.606)$ & $(2.292)$ \\
\hline \multirow[t]{2}{*}{ Log Notional Amount } & 0.0272 & 0.0249 & $0.224^{* * *}$ & $0.237^{* * *}$ & $0.262^{* * *}$ & $0.265^{* * *}$ \\
\hline & $(0.0321)$ & $(0.0327)$ & $(0.0278)$ & $(0.0336)$ & $(0.0134)$ & $(0.0142)$ \\
\hline \multirow[t]{2}{*}{ N. of Trades } & $-0.0019^{* * *}$ & -0.0007 & $-0.0011^{* * *}$ & -0.0006 & $-0.0016^{* * *}$ & $-0.0011^{* * *}$ \\
\hline & $(0.0003)$ & $(0.0004)$ & $(0.0002)$ & $(0.0003)$ & $(0.0001)$ & $(0.0001)$ \\
\hline \multirow[t]{2}{*}{ Constant } & -0.208 & 0.424 & $-3.917^{* * *}$ & $-3.870^{* * *}$ & $-4.541^{* * *}$ & $-4.558^{* * *}$ \\
\hline & $(0.568)$ & $(0.644)$ & $(0.471)$ & $(0.593)$ & $(0.242)$ & $(0.271)$ \\
\hline Observations & 832 & 832 & 1,713 & 1,713 & 5,132 & 5,132 \\
\hline Adj R2 & 0.0614 & 0.147 & 0.140 & 0.157 & 0.0987 & 0.136 \\
\hline Month FE & $\mathrm{N}$ & $\mathrm{Y}$ & $\mathrm{N}$ & $\mathrm{Y}$ & $\mathrm{N}$ & $\mathrm{Y}$ \\
\hline
\end{tabular}

Robust standard errors in parentheses: ${ }^{* * *} p<0.01,{ }^{* *} p<0.05,{ }^{*} p<0.1$ 
Table 5: Hypothesis 2: Position with the CCP

This table shows the estimated probit model results for contracts having Germany France and Italy as reference entity, and where both of the counterparties are clearing members (CM). The dependent variable is a dummy variable equal to one when the contract is cleared. Panel A shows the estimation results when considering the buyer side. The first explanatory variable is a dummy equal to one when the buyer is a net seller with the CCP. Panel B indicates the estimation results when considering the seller side. The first explanatory variable is a dummy equal to one when the seller is a net buyer with the CCP. In the models presented in the last two columns of the table, controls for month fixed effects are included.

Panel A

\begin{tabular}{|c|c|c|c|c|c|c|}
\hline \multirow[b]{2}{*}{ Variables } & \multicolumn{2}{|c|}{$\mathrm{DE}$} & \multicolumn{2}{|c|}{ FR } & \multicolumn{2}{|c|}{ IT } \\
\hline & (1) & $(2)$ & (3) & (4) & (5) & $(6)$ \\
\hline \multirow{2}{*}{$\begin{array}{l}\text { Buyer is net seller with } \\
\text { CCP (Dummy) }\end{array}$} & $0.598^{* *}$ & 0.303 & $0.886^{* * *}$ & $0.775^{* * *}$ & $0.130 * * *$ & $0.140 * * *$ \\
\hline & $(0.299)$ & $(0.319)$ & $(0.122)$ & $(0.128)$ & $(0.047)$ & $(0.049)$ \\
\hline \multirow[t]{2}{*}{ Constant } & $-0.598^{* * *}$ & $-0.319 * *$ & $-0.820^{* * *}$ & -0.249 & $-0.297^{* * *}$ & 0.008 \\
\hline & $(0.043)$ & $(0.160)$ & $(0.032)$ & $(0.153)$ & $(0.018)$ & $(0.090)$ \\
\hline Observations & 224 & 205 & 416 & 416 & 2,159 & 2,159 \\
\hline \multirow[t]{3}{*}{ Adj R2 } & 0.003 & 0.110 & 0.024 & 0.059 & 0.001 & 0.0431 \\
\hline & \multicolumn{4}{|c|}{ Panel B } & & \\
\hline & \multicolumn{2}{|c|}{$\mathrm{DE}$} & \multicolumn{2}{|c|}{ FR } & \multicolumn{2}{|c|}{ IT } \\
\hline Variables & (1) & $(2)$ & $(3)$ & (4) & (5) & (6) \\
\hline \multirow[t]{2}{*}{$\begin{array}{l}\text { Seller is net buyer with } \\
\text { CCP (Dummy) }\end{array}$} & $-1.008^{* * *}$ & $-0.946^{* * *}$ & $-0.907^{* * *}$ & $-0.976^{* * *}$ & $-0.304^{* * *}$ & $-0.279^{* * *}$ \\
\hline & $(0.135)$ & $(0.152)$ & $(0.0877)$ & $(0.098)$ & $(0.0349)$ & $(0.036)$ \\
\hline \multirow[t]{2}{*}{ Constant } & $0.305^{* *}$ & $0.628^{* * *}$ & 0.0156 & $0.806^{* * *}$ & $-0.076^{* * *}$ & $0.266^{* * *}$ \\
\hline & $(0.128)$ & $(0.220)$ & $(0.081)$ & $(0.168)$ & $(0.028)$ & $(0.097)$ \\
\hline Observations & 199 & 199 & 456 & 456 & 2,251 & 2,251 \\
\hline Adj R2 & 0.048 & 0.146 & 0.0493 & 0.089 & 0.009 & 0.049 \\
\hline Month FE & $\mathrm{N}$ & $\mathrm{Y}$ & $\mathrm{N}$ & $\mathrm{Y}$ & $\mathrm{N}$ & $\mathrm{Y}$ \\
\hline
\end{tabular}

Robust standard errors in parentheses: ${ }^{* * *} p<0.01,{ }^{* *} p<0.05,{ }^{*} p<0.1$ 
Table 6: Hypothesis 2: Position with the CCP

This table shows the estimated probit model results for contracts having Germany France and Italy as reference entity, and where both of the counterparties are clearing members (CM). The dependent variable is a dummy variable equal to one when the contract is cleared. Panel A shows the estimation results when considering the buyer side. The interaction term is the variable to analyze, capturing the jointed effect between two terms: The first one (A) is a dummy equal to one when the buyer is a net seller with the CCP for the respective sovereign CDS; the second one (B) indicates the buyer's exposure to the CCP. Panel B indicates the estimation results when considering the seller side. In this case the interaction term captures the combinations of two effects: the first variable (A) is a dummy equal to one when the seller is a net buyer with the CCP for the respective sovereign CDS. The second variable (B) indicates the seller's exposure to the CCP. In the models presented in the third and the sixth columns of the table, controls for month fixed effects are included.

Panel A

\begin{tabular}{|c|c|c|c|c|c|c|}
\hline \multirow[b]{2}{*}{ Variables } & \multicolumn{2}{|c|}{$\mathrm{DE}$} & \multicolumn{2}{|c|}{ FR } & \multicolumn{2}{|c|}{ IT } \\
\hline & $(1)$ & $(2)$ & $(3)$ & $(4)$ & $(5)$ & $(6)$ \\
\hline \multirow[t]{2}{*}{ Buyer - Interaction term $(\mathrm{A})^{*}(\mathrm{~B})$} & -0.645 & $-146.1^{* * *}$ & $4.131^{* * *}$ & $6.025^{* * *}$ & $4.316^{* * *}$ & $5.376^{* * *}$ \\
\hline & $(7.031)$ & $(4.897)$ & $(1.354)$ & $(2.011)$ & $(0.388)$ & $(0.418)$ \\
\hline \multirow[t]{2}{*}{ Buyer is net seller with CCP dummy (A) } & -0.0881 & $-22.11^{* * *}$ & $1.084^{* * *}$ & 0.515 & $0.560^{* * *}$ & $0.608^{* * *}$ \\
\hline & $(0.660)$ & $(0.492)$ & $(0.307)$ & $(0.364)$ & $(0.0786)$ & $(0.0866)$ \\
\hline \multirow[t]{2}{*}{ Buyer's exposure to the CCP (B) } & $-0.814^{* * *}$ & $-0.584^{* *}$ & $-0.837^{* * *}$ & $-4.132^{* *}$ & $-0.503^{* * *}$ & $-1.037^{* * *}$ \\
\hline & $(0.212)$ & $(0.279)$ & $(0.299)$ & $(1.694)$ & $(0.142)$ & $(0.158)$ \\
\hline \multirow[t]{2}{*}{ Constant } & -0.0285 & $1.455^{* * *}$ & $-0.286^{* * *}$ & 0.389 & -0.0127 & $0.824^{* * *}$ \\
\hline & $(0.107)$ & $(0.529)$ & $(0.0824)$ & $(0.367)$ & $(0.0361)$ & $(0.213)$ \\
\hline Observations & 224 & 205 & 416 & 416 & 2,159 & 2,159 \\
\hline \multirow[t]{3}{*}{ Adj R2 } & 0.0523 & 0.187 & 0.0432 & 0.201 & 0.0902 & 0.164 \\
\hline & \multicolumn{4}{|c|}{ Panel B } & & \\
\hline & \multicolumn{2}{|c|}{$\mathrm{DE}$} & \multicolumn{2}{|c|}{ FR } & \multicolumn{2}{|c|}{ IT } \\
\hline Variables & (1) & $(2)$ & $(3)$ & $(4)$ & $(5)$ & $(6)$ \\
\hline Seller - Interaction term $(\mathrm{A}) *(\mathrm{~B})$ & $\begin{array}{c}-7.179^{* *} \\
(3.658)\end{array}$ & $\begin{array}{c}13.07 \\
(9.086)\end{array}$ & $\begin{array}{c}-0.865^{*} \\
(0.511)\end{array}$ & $\begin{array}{c}-0.00776 \\
(0.631)\end{array}$ & $\begin{array}{c}-1.117^{* * *} \\
(0.252)\end{array}$ & $\begin{array}{c}-2.024^{* * *} \\
(0.259)\end{array}$ \\
\hline Seller is net buyer with CCP Dummy (A) & $\begin{array}{c}0.338 \\
(0.256)\end{array}$ & $\begin{array}{c}3.751^{* * *} \\
(1.382)\end{array}$ & $\begin{array}{l}0.0584 \\
(0.161)\end{array}$ & $\begin{array}{c}-1.316^{* * *} \\
(0.323)\end{array}$ & $\begin{array}{c}0.247^{* *} \\
(0.101)\end{array}$ & $\begin{array}{c}0.576^{* * *} \\
(0.109)\end{array}$ \\
\hline Seller's exposure to the CCP (B) & $\begin{array}{c}5.834 \\
(3.646)\end{array}$ & $\begin{array}{c}-18.72^{*} \\
(10.53)\end{array}$ & $\begin{array}{c}-0.713^{*} \\
(0.372)\end{array}$ & $\begin{array}{l}-0.256 \\
(0.404)\end{array}$ & $\begin{array}{l}0.191^{*} \\
(0.105)\end{array}$ & $\begin{array}{c}0.284^{* *} \\
(0.112)\end{array}$ \\
\hline Constant & $\begin{array}{c}0.423^{* * *} \\
(0.139)\end{array}$ & $\begin{array}{c}-2.081^{*} \\
(1.213)\end{array}$ & $\begin{array}{l}-0.115 \\
(0.104)\end{array}$ & $\begin{array}{c}0.827^{* * *} \\
(0.262)\end{array}$ & $\begin{array}{l}-0.0478 \\
(0.0323)\end{array}$ & $\begin{array}{c}0.347^{*} \\
(0.184)\end{array}$ \\
\hline Observations & 199 & 199 & 456 & 456 & 2,251 & 2,251 \\
\hline Adj R2 & 0.102 & 0.265 & 0.0744 & 0.182 & 0.00714 & 0.0668 \\
\hline Month FE & $\mathrm{N}$ & $\mathrm{Y}$ & $\mathrm{N}$ & $\mathrm{Y}$ & $\mathrm{N}$ & $\mathrm{Y}$ \\
\hline
\end{tabular}

Robust standard errors in parentheses: ${ }^{* * *} p<0.01,{ }^{* *} p<0.05,{ }^{*} p<0.1$ 


\section{Table 7: Hypothesis 3: Counterparty Credit Risk}

This table shows the estimated probit model results for contracts having Germany France and Italy as reference entity, and where both of the counterparties are clearing members $(\mathrm{CM})$. The dependent variable is a dummy variable equal to one when the contract is cleared. Panel A reports the impact of the buyer CDS spread on the probability to find a contract cleared. Panel B reports the impact of the seller CDS spread on the probability to find a contract cleared. Month fixed effects controls are included.

\section{Panel A}

\begin{tabular}{ccccccc}
\hline & \multicolumn{2}{c}{ DE } & \multicolumn{2}{c}{ FR } & \multicolumn{2}{c}{ IT } \\
\cline { 2 - 7 } Models & $(\mathbf{1})$ & $(\mathbf{2})$ & $\mathbf{( 3 )}$ & $\mathbf{( 4 )}$ & $\mathbf{( 5 )}$ & $(\mathbf{6})$ \\
\hline \multirow{2}{*}{ Spread Buyer - 5Y } & $0.010^{* * *}$ & $0.025^{* * *}$ & $0.010^{* * *}$ & $0.020^{* * *}$ & $0.004^{* * *}$ & $0.0066^{* * *}$ \\
& $(0.003)$ & $(0.003)$ & $(0.002)$ & $(0.003)$ & $(0.001)$ & $(0.0009)$ \\
Constant & $-2.035^{* * *}$ & $-3.272^{* * *}$ & $-2.193^{* * *}$ & $-2.341^{* * *}$ & $-1.083^{* * *}$ & $-1.271^{* * *}$ \\
& $(0.298)$ & $(0.463)$ & $(0.249)$ & $(0.377)$ & $(0.079)$ & $(0.144)$ \\
\hline Observations & 751 & 751 & 1,601 & 1,601 & 4,162 & 4,162 \\
Adj R2 & 0.017 & 0.121 & 0.014 & 0.073 & 0.004 & 0.0431
\end{tabular}

Panel B

\begin{tabular}{ccccccc}
\hline & \multicolumn{2}{c}{ DE } & \multicolumn{2}{c}{ FR } & \multicolumn{2}{c}{ IT } \\
\cline { 2 - 7 } Models & $\mathbf{( 1 )}$ & $\mathbf{( 2 )}$ & $\mathbf{( 3 )}$ & $\mathbf{( 4 )}$ & $\mathbf{( 5 )}$ & $\mathbf{( 6 )}$ \\
\hline Spread Seller - 5Y & $0.013^{* * *}$ & $0.025^{* * *}$ & $0.019^{* * *}$ & $0.023^{* * *}$ & $0.012^{* * *}$ & $0.0154^{* * *}$ \\
& $(0.003)$ & $(0.003)$ & $(0.002)$ & $(0.003)$ & $(0.001)$ & $(0.0010)$ \\
Constant & $-2.226^{* * *}$ & $-3.197^{* * *}$ & $-3.055^{* * *}$ & $-2.803^{* * *}$ & $-1.938^{* * *}$ & $-1.677^{* * *}$ \\
& $(0.282)$ & $(0.435)$ & $(0.197)$ & $(0.344)$ & $(0.088)$ & $(0.147)$ \\
\hline Observations & 768 & 768 & 1,638 & 1,638 & 4,176 & 4,176 \\
Adj R2 & 0.027 & 0.145 & 0.092 & 0.144 & 0.052 & 0.110 \\
\hline Month FE & & & & & $\mathrm{Y}$ & $\mathrm{N}$ \\
\hline
\end{tabular}

Robust standard errors in parentheses: ${ }^{* * *} p<0.01,{ }^{* *} p<0.05,{ }^{*} p<0.1$ 
Table 8: Hypothesis 3: Counterparty Credit Risk estimations for Italian sovereign CDS

This table shows the estimated probit model results for the contracts having Italy as reference entities, and where counterparties are clearing members (CM). The dependent variable is a dummy variable equal to one when the contract is cleared. The explanatory variables used are the buyer CDS spread (Spread Buyer 5Y) and the seller CDS spread (Spread Seller 5Y), both with 5 year tenors. In the models presented in the second column of the table, controls for month fixed effects are included.

\begin{tabular}{ccc}
\hline Models & $\mathbf{( 1 )}$ & $\mathbf{( 2 )}$ \\
\hline Spread Buyer - 5Y & $0.005^{* * *}$ & $0.008^{* * *}$ \\
Spread Seller- 5Y & $(0.001)$ & $(0.001)$ \\
Constant & $0.0097^{* * *}$ & $0.0119^{* * *}$ \\
& $(0.001)$ & $(0.002)$ \\
Observations & $-3.158^{* * *}$ & $-4.669^{* * *}$ \\
Adj R2 & $(0.129)$ & $(0.413)$ \\
\hline Month FE & 2,814 & 2,226 \\
\hline Robust standard errors in parentheses: & $* * * p<0.01, * * p<0.05,{ }^{*} p<0.1$
\end{tabular}




\section{Appendix}

Table 9: Hypothesis 1: Contract and Liquidity Risk estimations for German sovereign CDS

This table shows the estimated probit model results for contracts having Germany as reference entity, and where both of the counterparties are clearing members (CM). The dependent variable is a dummy variable equal to one when the contract is cleared. The explanatory variables used are: the CDS spread of the reference entity (CDS Quote Spread), the first difference of the CDS spread ( $\triangle$ CDS Spread), the logarithm of the Notional amount of the contract (Log Notional Amount), the exponential weighted moving average of the CDS returns of the reference entity (CDS Volatility), the number of the daily transactions (N. of trades).

\begin{tabular}{|c|c|c|c|c|c|}
\hline \multicolumn{6}{|c|}{$\mathrm{DE}$} \\
\hline Models & $(1)$ & $(2)$ & $(3)$ & $(4)$ & $(5)$ \\
\hline \multirow[t]{2}{*}{ CDS Quote Spread } & 0.0033 & & & & \\
\hline & $(0.0043)$ & & & & \\
\hline \multirow[t]{2}{*}{$\Delta$ CDS Spread } & & -0.149 & & & \\
\hline & & $(0.0965)$ & & & \\
\hline \multirow[t]{2}{*}{ Log Notional Amount } & & & 0.0081 & & \\
\hline & & & $(0.0260)$ & & \\
\hline \multirow[t]{2}{*}{ CDS Volatility } & & & & -2.075 & \\
\hline & & & & $(2.854)$ & \\
\hline \multirow[t]{2}{*}{ N. of Trades } & & & & & $-0.0018^{* * *}$ \\
\hline & & & & & $(0.0002)$ \\
\hline \multirow[t]{2}{*}{ Constant } & $-0.663^{* * *}$ & $-0.628^{* * *}$ & $-0.720^{*}$ & $-0.442^{* * *}$ & $-0.216^{* * *}$ \\
\hline & $(0.0714)$ & $(0.0432)$ & $(0.432)$ & $(0.0941)$ & $(0.0633)$ \\
\hline Observations & 989 & 989 & 1,004 & 832 & 1,004 \\
\hline Adj R2 & 0.0005 & 0.002 & 0.0001 & 0.0005 & 0.0551 \\
\hline Month FE & $\mathrm{N}$ & $\mathrm{N}$ & $\mathrm{N}$ & $\mathrm{N}$ & $\mathrm{N}$ \\
\hline
\end{tabular}

Robust standard errors in parentheses: ${ }^{* * *} p<0.01,{ }^{* *} p<0.05,{ }^{*} p<0.1$ 
Table 10: Hypothesis 1: Contract and Liquidity Risk estimations for French sovereign CDS

This table shows the estimated probit model results for contracts having France as reference entity, and where both of the counterparties are clearing members (CM). The dependent variable is a dummy variable equal to one when the contract is cleared. The explanatory variables used are: the CDS spread of the reference entity (CDS Quote Spread), the first difference of the CDS spread ( $\triangle$ CDS Spread), the logarithm of the Notional amount of the contract (Log Notional Amount), the exponential weighted moving average of the CDS returns of the reference entity (CDS Volatility), the number of the daily transactions (N. of trades).

\begin{tabular}{|c|c|c|c|c|c|}
\hline \multicolumn{6}{|c|}{ FR } \\
\hline Models & $(1)$ & $(2)$ & $(3)$ & $(4)$ & $(5)$ \\
\hline \multirow[t]{2}{*}{ CDS Quote Spread } & $0.0064^{* * *}$ & & & & \\
\hline & $(0.0021)$ & & & & \\
\hline \multirow[t]{2}{*}{$\Delta \mathrm{CDS}$ Spread } & & $-0.105^{* *}$ & & & \\
\hline & & $(0.0462)$ & & & \\
\hline \multirow[t]{2}{*}{ Log Notional Amount } & & & $0.211^{* * *}$ & & \\
\hline & & & $(0.0241)$ & & \\
\hline \multirow[t]{2}{*}{ CDS Volatility } & & & & $-7.759^{* * *}$ & \\
\hline & & & & $(2.602)$ & \\
\hline \multirow[t]{2}{*}{ N. of Trades } & & & & & $-0.0012^{* * *}$ \\
\hline & & & & & $(0.0002)$ \\
\hline \multirow[t]{2}{*}{ Constant } & $-0.966^{* * *}$ & $-0.766^{* * *}$ & $-4.121^{* * *}$ & $-0.511^{* * *}$ & $-0.554^{* * *}$ \\
\hline & $(0.0715)$ & $(0.0314)$ & $(0.395)$ & $(0.0727)$ & $(0.0467)$ \\
\hline Observations & 1,997 & 1,997 & 2,034 & 1,716 & 2,034 \\
\hline Adj R2 & 0.0052 & 0.0051 & 0.0935 & 0.0059 & 0.0170 \\
\hline Month FE & $\mathrm{N}$ & $\mathrm{N}$ & $\mathrm{N}$ & $\mathrm{N}$ & $\mathrm{N}$ \\
\hline
\end{tabular}

Robust standard errors in parentheses: ${ }^{* * *} p<0.01,{ }^{* *} p<0.05,{ }^{*} p<0.1$ 
Table 11: Hypothesis 1: Contract and Liquidity Risk estimations for Italian sovereign CDS

This table shows the estimated probit model results for contracts having Italy as reference entity, and where both of the counterparties are clearing members $(\mathrm{CM})$. The dependent variable is a dummy variable equal to one when the contract is cleared. The explanatory variables used are: the CDS spread of the reference entity (CDS Quote Spread), the first difference of the CDS spread ( $\triangle$ CDS Spread), the logarithm of the Notional amount of the contract (Log Notional Amount), the exponential weighted moving average of the CDS returns of the reference entity (CDS Volatility), the number of the daily transactions (N. of trades).

\begin{tabular}{|c|c|c|c|c|c|}
\hline \multicolumn{6}{|c|}{ IT } \\
\hline Models & $(1)$ & $(2)$ & $(3)$ & $(4)$ & $(5)$ \\
\hline \multirow[t]{2}{*}{ CDS Quote Spread } & 0.0004 & & & & \\
\hline & $(0.0004)$ & & & & \\
\hline \multirow[t]{2}{*}{$\Delta$ CDS Spread } & & $0.0085^{* *}$ & & & \\
\hline & & $(0.0035)$ & & & \\
\hline \multirow[t]{2}{*}{ Log Notional Amount } & & & $0.263^{* * *}$ & & \\
\hline & & & $(0.0123)$ & & \\
\hline \multirow[t]{2}{*}{ CDS Volatility } & & & & 0.742 & \\
\hline & & & & $(1.460)$ & \\
\hline \multirow[t]{2}{*}{ N. of Trades } & & & & & $-0.0016^{* * *}$ \\
\hline & & & & & $(0.0001)$ \\
\hline \multirow[t]{2}{*}{ Constant } & $-0.336^{* * *}$ & $-0.282^{* * *}$ & $-4.598^{* * *}$ & $-0.289^{* * *}$ & $-0.0822^{* * *}$ \\
\hline & $(0.0544)$ & $(0.0166)$ & $(0.206)$ & $(0.0435)$ & $(0.0220)$ \\
\hline Observations & 5,925 & 5,925 & 5,816 & 5,282 & 5,985 \\
\hline Adj R2 & 0.0001 & 0.0007 & 0.0846 & $3.51 \mathrm{e}-05$ & 0.0186 \\
\hline Month FE & $\mathrm{N}$ & $\mathrm{N}$ & $\mathrm{N}$ & $\mathrm{N}$ & $\mathrm{N}$ \\
\hline
\end{tabular}

Robust standard errors in parentheses: ${ }^{* * *} p<0.01,{ }^{* *} p<0.05,{ }^{*} p<0.1$ 


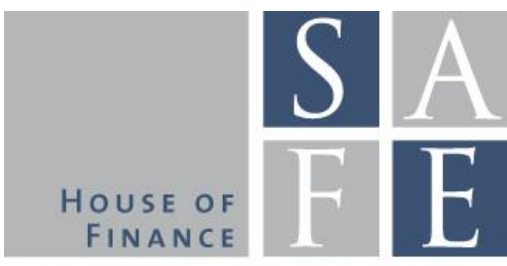

WORKING PAPER SERIES

\section{Recent Issues}

No. 192 Vincenzo Pezone

No. 191 Julia Hirsch, Uwe Walz

No.190 Vanya Horneff, Raimond Maurer, Olivia S. Mitchell

No. 189 Carlo Wix

No. 188 Michael Donadelli, Patrick Grüning, Marcus Jüppner, Renatas Kizys

No. 187 Baptiste Massenot, Yuri Pettinicchi

No. 186 Nicole Branger, Paulo Rodrigues, Christian Schlag

No. 185 Patrick Grüning

No. 184 Tobias Tröger

No. 183 Joost Driessen, Theo E. Nijman, Zorka Simon

No. 182 Mario Bellia, Loriana Pelizzon, Marti G. Subrahmanyam, Jun Uno, Darya Yuferova

No. 181 Holger Kraft, Farina Weiss
The Real Effects of Judicial Enforcement:

Evidence from Italy

Financial constraints, newly founded firms and the financial crisis

How Persistent Low Expected Returns Alter Optimal Life Cycle Saving, Investment, and Retirement Behavior

The Long-Run Real Effects of Banking Crises: Firm-Level Investment Dynamics and the Role of Wage Rigidity

Global Temperature, R\&D Expenditure, and Growth

Can Firms see into the Future? Survey evidence from Germany

Level and Slope of Volatility Smiles in LongRun Risk Models

Heterogeneity in the Internationalization of R\&D: Implications for Anomalies in Finance and Macroeconomics

Remarks on the German Regulation of Crowdfunding

The Missing Piece of the Puzzle: Liquidity Premiums in Inflation-Indexed Markets

Coming Early to the Party

Consumption-Portfolio Choice with Preferences for Cash 